Portland State University

PDXScholar

$1-1-1985$

\title{
Cathodic depositions of the compound semiconductor cadmium sulfide
}

Jeffrey B. Richard

Portland State University

Follow this and additional works at: https://pdxscholar.library.pdx.edu/open_access_etds Let us know how access to this document benefits you.

\section{Recommended Citation}

Richard, Jeffrey B., "Cathodic depositions of the compound semiconductor cadmium sulfide" (1985). Dissertations and Theses. Paper 571.

https://doi.org/10.15760/etd.571

This Dissertation is brought to you for free and open access. It has been accepted for inclusion in Dissertations and Theses by an authorized administrator of PDXScholar. Please contact us if we can make this document more accessible: pdxscholar@pdx.edu. 


\title{
CATHODIC DEPOSITIONS OF THE COMPOUND SEMICONDUCTOR CADMIUM SULFIDE
}

\author{
by \\ JEFFREY B . RICHARD
}

A dissertation submitted in partial fulfillment of the requirements for the degree of

DOCTOR OF PHILOSOPHY in

ENVIRONMENTAL SCIENCES AND RESOURCES/CHEMISTRY

Portland State University

1985 
TO THE OFFICE OF GRADUATE STUDIES AND RESEARCH:

The members of the Committee approve the dissertation of Jeffrey B. Richard presented May 30, 1985.
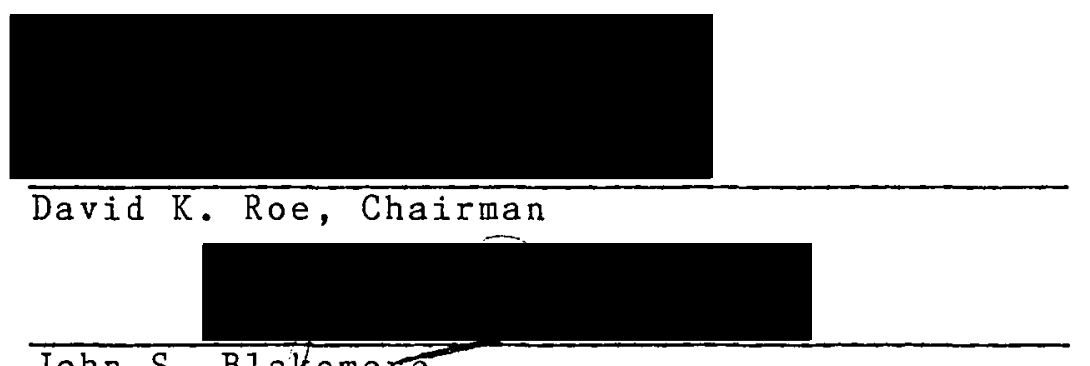

John S. BHakemore

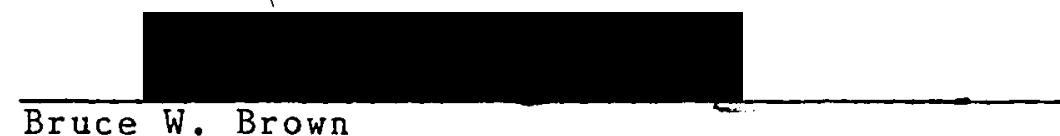

Bruce W. Brown

Stanley S./Hiliman

Dona1d G. Howard

APPROVED :

Richard R. Petersen, Acting Director, Environmental Science and Resources

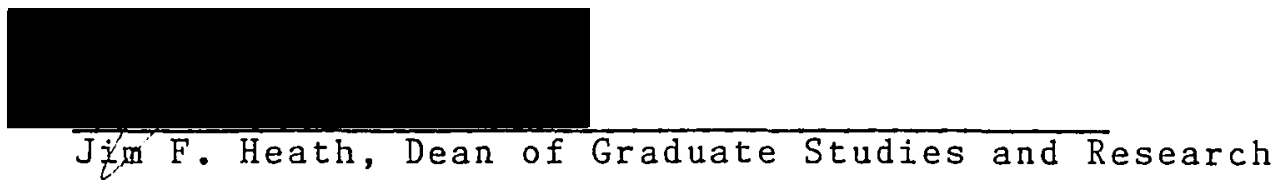




\section{DEDICATION}

This paper is dedicated to the idea that power is abundant and should be made available to all. 


\section{ACKNOWLEDGEMENTS}

I thank the members of my committee for their time and criticism. Special thanks are extended to Professor Bruce Brown for his aid with the Honeywell computer and to Professor John Blakemore for his patience in reviewing the EPS materia1. Thanks are also extended to Mario Aparicio-Razo and Howard Hogle for doing much of the preliminary work and for being peers in need.

Appreciation is extended to Dennis Clark for his navigational skills through seas of supplies, equipment, and bureaucracy; to Peg Pankratz who knew, or knew who knew, administrative details; to Julie Schemmel for helping in a pinch; to Rudolph Zupan and Garo Arakelian for machining much of the equipment; to Gary Lemoine for typing this manuscript and numerous drafts, and to all my friends, roommates, family, fellow graduate students and Portland State University faculty whose patience and warm cheer lightened my days and kept things in perspective.

My most substantial thanks are offered to Professor David Roe whose patience, direction and insight endured through many difficult periods. 
TABLE OF CONTENTS

PAGE

DEDICATION • • • • • • • • • • • • • • • • • • • •

ACKNOWLEDGEMENTS • • • • . • • • • • • • • • • • IV

LIST OF FIGURES • . • • • • • • • • • • • • • • • • vii

CHAPTER

I INTRODUCTION . . . . . . . . . . . . . . . 1

II EXPERIMENTAL • . . . . . . . . . . . 8

Chemicals \& Equipment • • . . . . . . 8

Cadmium Sulfide Depositions . . . . . 10

Measurement of Photoproperties . . . . . 12

Filtration through Cadmium Metal . . . . 14

Electrochemistry of Bulk Sulfur . . . . . 14

Electrochemistry of Sulfur using HPLC . . 15

Sulfur Reduction on Gold

Kinetic Effects on Gold

Sulfur Reduction on Porous Carbon

Sulfur Reduction on Cadmium Sulfide

$\mathrm{S}_{7}$ Experiments • • • • • • • • • • • • 19

Electrochemical Photocapacitance Spectra • 20

III RESULTS . . . . . . . . . . . . . 21

Deposition Conditions for CdS . . . . . 21

Temperature

Current Density

Sulfur Concentration

Cadmium Concentration

Doping with Bismuth Ion 


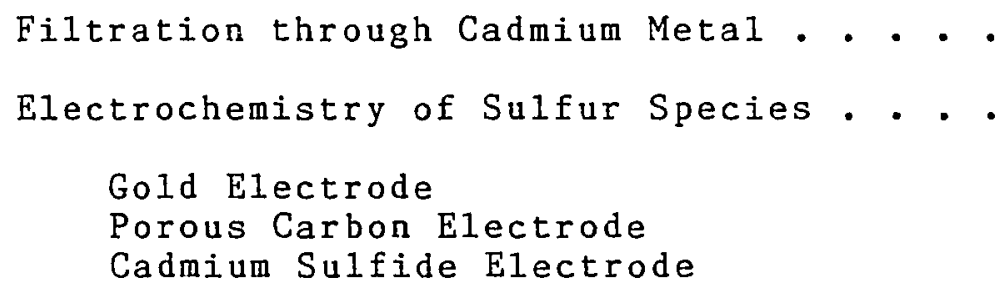


LIST OF FIGURES

FIGURE

PAGE

1. Sunlamp Intensity . . . . . . . . . . . 13

2. Equipment of HPLC Electrochemical Measurements . . 16

3. Typical Photoresponse Tests of CdS . . . . . . 22

4. Photoreponse as a Function of Temperature . . . . 24

5. Limiting Current of Sulfur . . . . . . . . . 25

6. Photoresponse as a Function of Current Density - . 26

7. Photoresponse versus Sulfur Concentration • • . 27

8. Photoresponse versus Cadmium Concentration . . . 28

9. Photoresponse versus Bismuth Doping Level • • - 30

10. Sulfur Reduction on Gold versus Potential . . . 32

11. Sulfur Reduction on Gold versus Flow Rate . . . 35

12. Sulfur Reduction on Porous Carbon versus Flow Rate 36

13. Sulfur Reduction on Cadmium Sulfide . . . . . . 38

14. Semiconductor Electrolyte Interface for EPS • . 43

15. Parameter Fitting Sequence for Photocapacitance

Analysis . . . . . . . . . . . . 47

16. EPS Spectrum and Analysis of p-GaP . . . . . . . 49

17. EPS Spectrum and Analysis of p-GaAs . . . . . . 50

18. EPS Spectrum and Analysis of $\mathrm{n}-\mathrm{CdS} . . . \cdot$. . . 51 
AN ABSTRACT OF THE DISSERTATION OF Jeffrey B. Richard for the Doctor of Philosophy in Environmental Sciences and Resources/ Chemistry presented May 30, 1985.

Title: Cathodic Depositions of the Compound Semiconductor Cadmium Sulfide.

APPROVED BY MEMBERS OF THE DISSERTATION COMMITTEE:

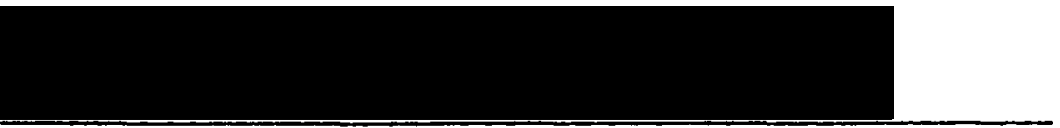

David K. Roe, Chairman

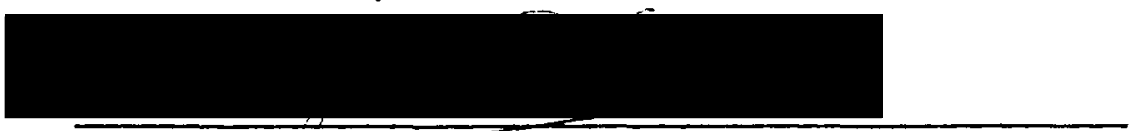

John S. B.Iakemore-

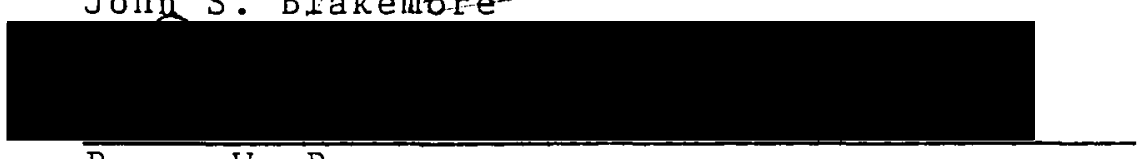

Bruce W. Brown

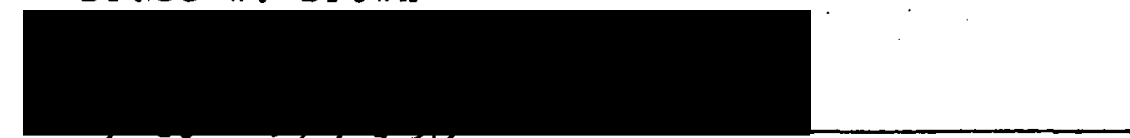

Stanley 8. HYIman

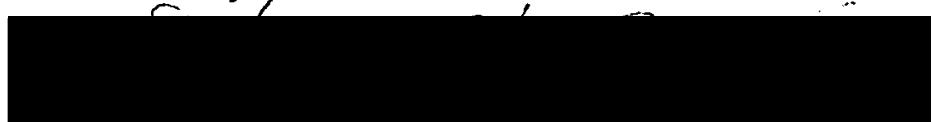

Dona1d G. Howard

The importance of developing photovoltaics as a future energy source is well established. Compound semiconductors have played an important role in this development because good efficiencies can be obtained due to the favorable band 
gaps of some of these semiconductors. The standard method of making these semiconductors involves growing high purity single crystals but this process is energy consuming and costly. Polycrystalline forms of these compounds have also been made with reasonable efficiencies and costs. of interest here are chalcogenides and in particular cadmium sulfide. It has been shown that many chalcogenides, especially slifides and selenides, can be cathodically deposited from a nonaqueous solition of a metallic salt and the elemental chalcogen. To make these polycrystalline deposits very little energy is needed and thus this method could be quite cost effective.

There are numerous parameters that can be controlled in this electrodeposition of cadmium sulfide including temperature, current density, concentrations of reactants and doping. It was found that the conditions which yield the highest photopower are $88^{\circ} \mathrm{C}$, a current density of 0.25 $\mathrm{mA} / \mathrm{cm}^{2}$, a cadmium chloride concentration of $0.2 \mathrm{~F}$, a sulfur concentration of $0.1 \mathrm{~F}$ sulfur atoms and a bismuth chloride doping concentration of $2 \times 10^{-8} \mathrm{~F}$.

The mechanism of this deposition is not fully understood mainly due to the complex chemistry of sulfur. Part of this complexity is the presence of $S_{6}$ and $S_{7}$ along with the major component $S_{8}$ in sulfur solutions. At equilibrium, these minor components are $2 \%$ of the sulfur at $90^{\circ}$. Fortunately their equilibrium is slow enough that they 
can be separated by HPLC. The reaction of these sulfur species with finely divided cadmium metal was followed. At room temperature $S_{7}$ is slightly more reactive and $S_{8}$ seems to adsorb strongly on the surface. With the solution at $90^{\circ}$ $\mathrm{S}_{7}$ is much more reactive and adsorption is less pronounced. The electrochemistry of these sulfur species was followed by electrochemical flow.cell detectors and a UV detector connected to the HPLC. On a gold electrode it was shown that the half wave potentials of $S_{6}, S_{7}$, and $S_{8}$ are respectively $-0.50 \mathrm{~V},-0.54 \mathrm{~V}$, and $-0.63 \mathrm{~V}$. Quantitative reduction on porous carbon was more complex. At flow rates below $0.4 \mathrm{ml} / \mathrm{min} \mathrm{S}_{8}$ was reduced by four electrons per molecule while at flow rates above $1.5 \mathrm{ml} / \mathrm{min} \mathrm{S}_{8}$ was reduced by only two electrons per molecule. $S_{6}$ was reduced at all flow rates by eight electrons per molecule. $S_{7}$ was reduced by eleven electrons per molecule except at flow rates below $1.0 \mathrm{~m} 1 / \mathrm{min}$ where $\mathrm{S}_{7}$ was decomposed in the UV detector. These electrochemical studies show that $\mathrm{S}_{6}$ and $\mathrm{S}_{7}$ are electrochemically more reactive than $S_{8}$ and thus may play an important role in the formation of the cadmium sulfide deposits.

In the past year there has been an important development in the measurement of midgap impurity levels of semiconductors. These impurity levels are important because they significantly alter the electrical properties of semiconductors. This new technique is called 
Electrochemical Photocapacitance Spectroscopy and can be used to analyse a wide variety of semiconductors. It works by shining subband gap light of the semiconductor in a photoelectrochemical cell while measuring the capacitance on the surface. Up to now interpretation of these spectra has been qualitative. A quantitative model is presented here along with a computer program utilizing this interpretation. This model assumes a Fermi distribution of the impurity levels to calculate the density of states versus the energy depth in the band gap. Cadmium sulfide deposits were analysed by this technique as well as other semiconductors. 
CHAPTER I

INTRODUCTION

The importance of photovoltaics for future electrical energy production is well recognized. Reducing their cost and improving their efficiency are both necessary for their future utilization. One form of photovoltaic that has gained substantial recognition is the thin layer cell. This type of solar cell improves efficiency by reducing electrical resistance. Even more importantly it reduces cost by decreasing the amount of material needed. Many of these thin layer photovoltaics are on the order of only one to ten microns thick ( 1 ).

Another important development in the field of photovoltaics is the variety of substances being investigated. Previously various forms of silicon dominated the field but more and more often different materials have been subject to research and breakthroughs, especially in the area of compound semiconductors. One reason these other semiconductors are potentially better than silicon is that they have band gaps that make them theoretically more efficient $(2,3)$. 
The compound of main interest here is cadmium sulfide (CdS). This compound has been made in thin film form by a variety of techniques such as vapor deposition (4), anodization of cadmium in sulfur solutions (5), and cathode deposition from aqueous solution ( 6 ).

Of main interest here is the cathodic deposition of CdS from nonaqueous solutions of elemental sulfur and a cadmium salt. This technique was discovered simultaneously by two groups $(7,8)$. The overall reaction for this deposition is

$$
\mathrm{Cd}^{+2}+\mathrm{S}+2 \mathrm{e}^{-}---\mathrm{CdS}
$$

There are many variables that can be controlled in making these deposits including substrate, solvent, electrolyte, type of cadmium salt (counter ion), cadmium concentration, sulfur concentration, temperature, rate of deposition (current density), and doping effects. The initial four parameters listed above were not investigated here although Baranski and Fawcett have studied these effects and noted that a) a variety of substrates can be used (8); b) the type of solvent used is important; and c) the anions present in solution also affect deposits (9). The latter five properties have been studied here by changing only one of these variables at a time. Each deposit made was tested in a photoelectrochemical cell (PEC) using a halogen lamp as the light source.

PEC's differ from photovoltaics in that the 
photo-active junction is a semiconductor/electrolyte interface rather than a $p-n$ or $p-i-n$ solid state junction. It is believed that these PEC's may be an important technology in future solar conversion technologies $(10,11)$. For this reason and the fact that this method is relatively simple to accomplish is why this technique was chosen. The main drawback to this testing method is the fact that CdS is unstable under illumination in most solutions. ThIs is because the illuminated CdS reduces itself (the reverse of reaction 1) which forms a passivating sulfur layer on the surface, rather than reducing the oxidizing agent of the redox couple in solution. This problem has been largely solved by use of aqueous polysulfide $(12,13)$. Although long range stability is yet a problem, this system is more than stable enough for the testing done here.

Another method of testing semiconductors which reveals quite different properties is Electrochemical Photocapacitance Spectroscopy (EPS). This method has been developed recently by Haak and Tench (14). It works by immersing the semiconductor in a PEC with a reverse bias and shining sub-bandgap monochromatic light. As the wavelength of the light is varied the capacitance of the surface of the semiconductor electrode is measured. Impurity levels in the band gap become filled or emptied due to the energy of the incident light which causes the charge, and thus the capacitance, on the surface of the electrode to change. 
Until now these spectra have been interpreted qualitatively. Presented here is a model which interprets the EPS results to give the amount of the impurities (density of states) as a function of depth in the band gap. EPS was done on samples of cathodically deposited CdS and the results are interpreted here along with the results of other semiconductors analysed by this technique. Because this topic is somewhat distinct from most of the other work presented here, a separate chapter is devoted to its discussion.

Besides the testing of these CdS deposits made under different conditions, studies of the mechanism of the deposit were also undertaken in the hopes that a better understanding of the process would guide us toward improving them. Roe, Li and Gerisher (7) have proposed two possible mechanisms for these deposits:

$$
\begin{array}{ll}
\mathrm{Cd}^{+2}+2 e^{-}-->\mathrm{Cd}^{\circ}(\operatorname{surf}) & 2 \mathrm{a} \\
\mathrm{Cd}{ }^{\circ}(\text { surf })+\mathrm{S}_{\mathrm{m}}-->\mathrm{CdS}+\mathrm{S}_{\mathrm{m}-1} & 2 \mathrm{~b}
\end{array}
$$

or

$$
\begin{aligned}
& S_{m}+2 e^{-}-->S^{-2} m(\operatorname{surf}) \\
& S^{-2}(\operatorname{surf})+C d^{+2}--\rightarrow C d S+S_{m-1}
\end{aligned}
$$

There is evidence that the mechanism may be dependant on the substrate. Roe, et al. (7) showed that reaction sequence 2 could be responsible for the initial layers formed on gold. Baranski and Fawcett (9) give evidence that reaction 
sequence 3 occurs on deposits of CdS and postulate that a similar mechanism occurs for the initial deposits.

The sulfur chemistry involved in these reactions is quite complicated. Adsorption of sulfur on the surface of the electrodes probably plays an important role (9). Aparicio-Razo performed rotating ring disk electrochemistry studies on $\mathrm{S}_{8}$ and calculated the heterogeneous rate constant for the two electron reduction (15). He also showed that at higher temperatures adsorption occurs on the gold electrode with complicating side reactions. Hogle showed that at $90^{\circ}$ sulfur reacts spontaneously with cadmium metal to form a complex mixture of polysulfides (16). He and Mondon (17) showed that the cadmium ion forms complexes with polysulfide species that are stable and quite soluble in dimethylsulfoxide (DMSO) solutions.

To complicate matters further $\mathrm{S}_{8}$ is not the only species present when an elemental sulfur solution is in equilibrium. Steudel et al. (18) showed that mixtures of sulfur rings could be separated by high pressure liquid chromatography (HPLC). Tebbe et al. (19) used this separation and showed that $S_{6}$ and $S_{7}$ are in equilibrium with $\mathrm{S}_{8}$ and present at above $1 \%$ in solution at room temperature. At higher temperatures, $S_{6}$ and $S_{7}$ are in greater concentration. $S_{6}$ is known to be more reactive than $S_{8}$, and $\mathrm{S}_{7}$ is also believed to be more reactive (19-23). Aparicio-Razo showed that $S_{6}$ and $S_{7}$ react differently than 
$\mathrm{S}_{8}$ with cadmium (15). This reactivity of sulfur species with cadmium has been further studied here. In addition, electrochemisty of each sulfur species was performed here by separating them in the HPLC and using electrochemical flow cell detectors. The flow cell electrodes used were gold, cadmium sulfide and porous carbon. The latter flow cell was used because the coulombic efficiency was very high and gives quantitative results. These electrochemical cells reveal much information about each of these sulfur species because they can test them separately. As will be shown later, these sulfur species do indeed react differently. An important snag in the path of this sulfur inquiry was the lack of information about $S_{7}$. Its isolation and synthesis was accomplished in 1968 (24), but no UV spectra of $\mathrm{S}_{7}$ was reported in the literature due to instability under UV 1ight (25). Aparicio-Razo had made a relative UV spectra (15) but without absolute measurements and thus a quantitative determination could not be made. For this reason $\mathrm{S}_{7}$ was isolated and some of its chemical and physical properties were investigated. This enabled quantitative values of $S_{7}$ to be determined, with some surprising results. When the results of all these individual studies and past research are put together, they reveal much about the formation of these CdS deposits. The EPS spectra reveal what kind of impurities present in the deposits are causing the low efficiencies. The sulfur chemistry studies explain 
how the impurities get there and also explain much about the CdS deposition conditions and its mechanism of formation. It is hoped that in the light of all of this information better CdS and other compound semiconductors can be made for solar cell applications. 
CHAPTER II

EXPER IMENTAL

Chemicals and Equipment

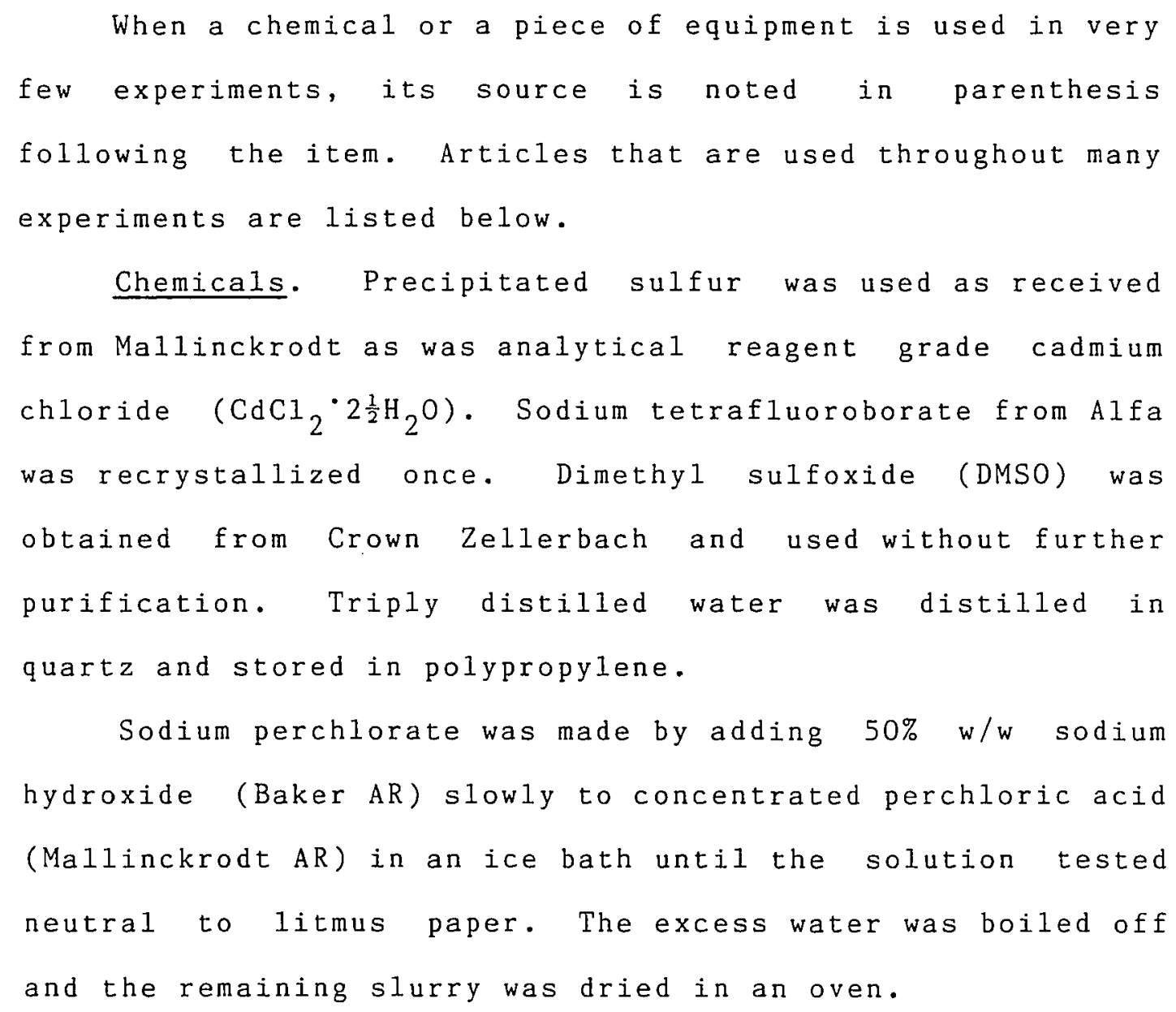

Chemicals. Precipitated sulfur was used as received from Mallinckrodt as was analytical reagent grade cadmium chloride $\left(\mathrm{CdCl}_{2} \cdot 2 \frac{1}{2} \mathrm{H}_{2} \mathrm{O}\right)$. Sodium tetrafluoroborate from Alfa was recrystallized once. Dimethyl sulfoxide (DMSO) was obtained from Crown Zellerbach and used without further purification. Triply distilled water was distilled in quartz and stored in polypropylene. Sodium perchlorate was made by adding $50 \%$ w/w sodium hydroxide (Baker AR) slowly to concentrated perchloric acid (Mallinckrodt $A R$ ) in an ice bath until the solution tested neutral to litmus paper. The excess water was boiled off and the remaining slurry was dried in an oven. 
Equipment. Equipment used is listed below, followed by manufacturer and model number:

Centigram balance, Torsion Balance Co., Torbal

Analytical balance, Mettler Instruments, Sauter 424

Potentiostat, Heka, PG284

Dual Pen Chart Recorder, Texas Instruments, FX22T6D

Digital Multimeter, Tektronix, DM501

Digital Multimeter, Data Precision, 245

X-Y Recorder, Hewlett Packard, 7040A

Computer, Honeywel1, 66/20

Computer, Hewlett Packard, HP7225B

Calculator, Hewlett Packard, HP25C

Thin Layer Flow Cell, Bioanalytical Systems, LC-17

Equipment used for HPLC analyses are as follows:

HPLC pump, Waters Associates, M-6000A

Sample injector, Rheodyne, 7125

Column, Altex, Ultrasphere ODS 254-05

Absorbance Detector, Waters Associates, 400

Dual Pen Chart Recorders, Texas Instruments, FX22T6D

Also used were an integrator, a bipotentiostat and a constant current device, all made at Portland State University. The integrator takes a 1 volt signal, integrates it with a 1 sec., 100 msec., or $10 \mathrm{msec}$. time constant and outputs the resulting voltage.

The bipotentiostat is a dual potentiostat whose two working electrodes can be operated independantly while they 
have common reference and counter electrodes. The potential range is plus or minus 2 volts with the current output of plus or minus 20 milliamperes.

The constant current device is a constant current source with current ranges of $0-1 \mathrm{~mA}$ and $0-10 \mathrm{~mA}$. It is powered by a 9 volt battery and was tested before each use. Cadmium Sulfide Depositions

Cadmium sulfide deposits were made in a 100 ml. three-neck flask immersed in a glycerol bath which rested on a combination magnetic stirrer/hot plate which stirred both the heating bath and solution. The solution contained sulfur, cadmium chloride and tenth molar sodium tetrafluoroborate electrolyte in dimethyl sulfoxide. Placed in this solution was a nitrogen bubbler, a cadmium counter electrode (anode) and of course the working electrode (cathode). The counter electrode was separated from the bulk solution by a glass frit and surrounded by $0.1 \mathrm{M} \mathrm{CdCl}_{2}$ in DMSO. The working electrode, usually gold foil, was suspended from a titanium clip and pretreated as follows; the foil is polished smooth and flattened, then sequentially washed with methanol, water, dilute $\mathrm{HNO}_{3}, \mathrm{I} / \mathrm{I} \mathrm{v} / \mathrm{v} \mathrm{H}_{2} \mathrm{O} /$ conc. HCl, water, and DMSO. The electrode is then connected to the counter electrode via a constant current device and immersed into the solution with the power on. Deposition continued until nominally one or, more often, two microns of CdS had deposited, assuming 100\% deposition efficiency. The 
sample was then immediately removed and tested for photoproperties.

Varied throughout these deposits were temperature, current density, $\mathrm{CdCl}_{2}$ and sulfur concentration. Also tested was the effect of $\mathrm{BiCl}_{3}$ as a dopant. Each variable was tested separately by fixing the remaining variables.

Temperature was varied from $60^{\circ}$ to $130^{\circ}$ in $10^{\circ}$ intervals while keeping $\left[\mathrm{CdCl}_{2}\right]=10 \mathrm{mM},[\mathrm{S}]=38 \mathrm{mM}$ and current density in the range of 0.14 to $0.18 \mathrm{~mA} / \mathrm{cm}^{2}$.

A second series of deposits were made varying temperature from $81^{\circ}$ to $99^{\circ}$ with $\left[\mathrm{CdCl}_{2}\right]=0.20 \mathrm{~F},[\mathrm{~S}]=0.10 \mathrm{~F}$, current density $=30+/-2 \mathrm{~mA} / \mathrm{cm}^{2}$ and $\left[\mathrm{BiCl}_{3}\right]=2.0 \times 10^{-8} \mathrm{~F}$.

While the current density was varied from 0.15 to $1.00 \mathrm{~mA} / \mathrm{cm}^{2}$ the other variables were fixed as follows: $\left[\mathrm{CdCl}_{2}\right]=50 \mathrm{mF}, \quad[\mathrm{S}]=100 \mathrm{mF}$ and temperature $=90^{\circ}$. Another set of measurements was made at $90^{\circ}$ with $\left[\mathrm{CdCl}_{2}\right]=5 \mathrm{mF}$ and $[\mathrm{S}]=10 \mathrm{mF}$.

Two sets of data of sulfur variance were made, one with $\left[\mathrm{CdCl}_{2}\right]=20 \mathrm{mM}$ and the other with $\left[\mathrm{CdCl}_{2}\right]=50 \mathrm{mM}$. Temperature was kept at $90^{\circ}$ while current density was in the range of 0.27 to $0.30 \mathrm{~mA} / \mathrm{cm}^{2}$. Sulfur concentration varied from $20 \mathrm{mM}$ to $190 \mathrm{mM}$ (saturation).

Similarly, a double set of cadmium concentration variance was made. $\left[\mathrm{CdCl}_{2}\right]$ varied from $20 \mathrm{mM}$ to $500 \mathrm{mM}$ while temperature was fixed at $90^{\circ}$, current density at 0.28 to $0.34 \mathrm{~mA} / \mathrm{cm}^{2}$ and [S] was kept at both $190 \mathrm{mM}$ and $100 \mathrm{mM}$. 
Lastly doping of the cadmium sulfide was attempted by adding $\mathrm{BiCl}_{3}$ (Matheson, Coleman \& Bell) to the deposition solution with the ratios of $\left[\mathrm{Bi}^{3+}\right] /\left[\mathrm{Cd}^{2+}\right]$ ranging in decades from $10^{-4}$ to $10^{-10}$. The other parameters were $\left[\mathrm{CdCl}_{2}\right]=200$ $\mathrm{mM}, \quad[\mathrm{S}]=100 \mathrm{mM}$, temperature $=90^{\circ}$ and current density was $0.30 \pm 0.02 \mathrm{~mA} / \mathrm{cm}^{2}$.

Measurement of Photoproperties

The cadmium sulfide samples were tested by immersing them in a redox solution with a platinum gauze counter electrode. The sample was illuminated with a quartz-iodine lamp (SLI-no.2062). The potential and current between the electrodes was metered by a potentiostat and registered on an $X-Y$ Recorder. Usually both light and dark voltage/current curves were measured by scanning at $1 \mathrm{mV} / \mathrm{sec}$ from the OCP to 0 volts.

The lamp intensity was calibrated at various distances using a Coherent 210 Power Meter. The results are shown in figure 1. A distance of $8 \mathrm{~cm}$. gives AMI 1ight which was generally used.

The redox solution used was a polysulfide solution which protects the semiconductor from photodecomposition (13). This aqueous solution consists of $1 \mathrm{~F} \mathrm{NaOH}, 1 \mathrm{~F} \mathrm{Na}_{2} \mathrm{~S}$ and $I F S$ atoms.

Error bars shown on photopower measurements are due to uncertainty in the CdS electrode surface area. All other 


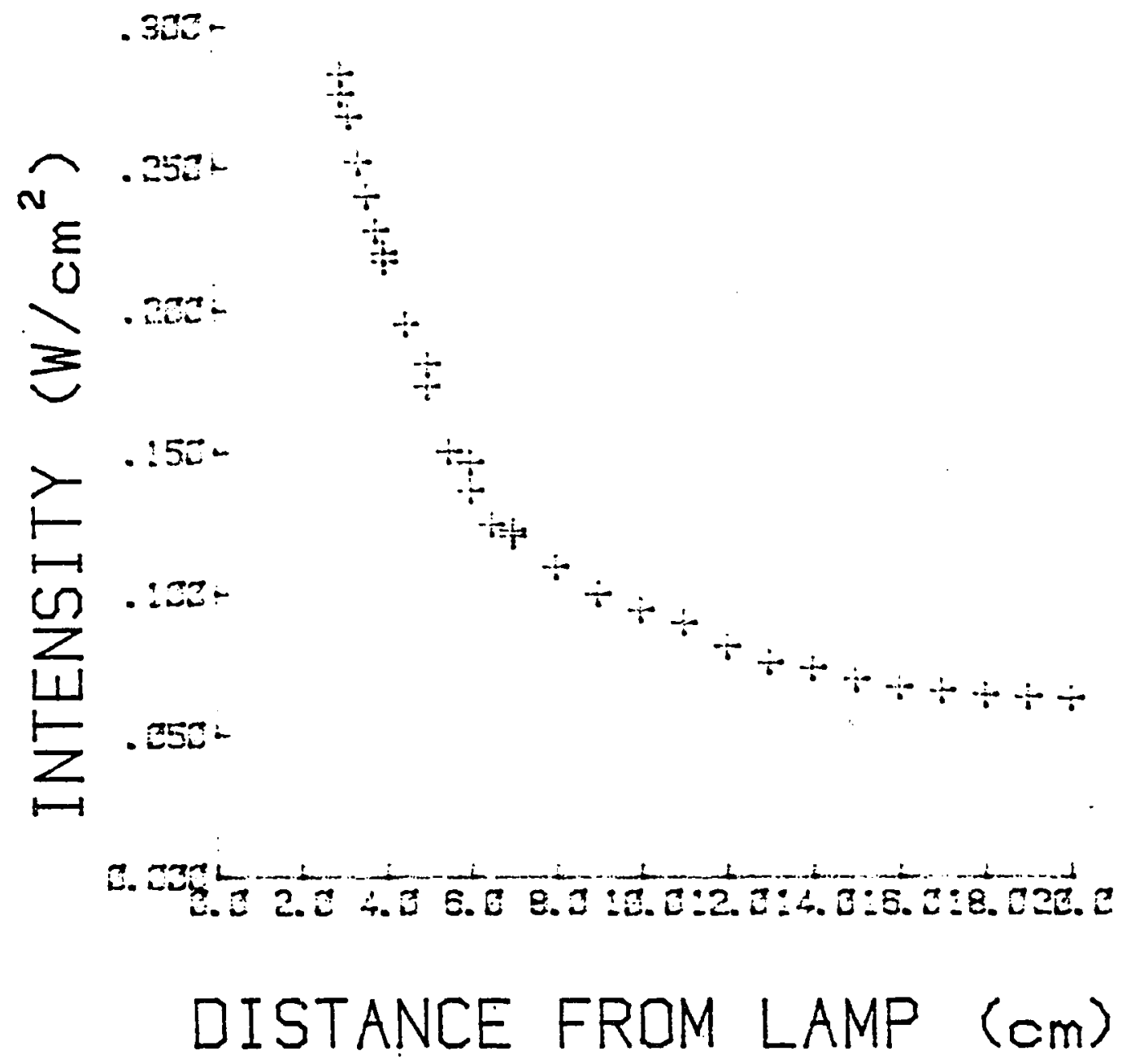

Figure 1. The intensity of the SII-no. 2062 quartz iodine lamp, used as a sun lamp to test the Cas deposits, as a function of distance. 
errors shown are standard deviations unless stated otherwise.

Filtrations through Cadmium Metal

In these experiments samples of sulfur in DMSO are filtered through finely divided cadmium metal. The samples are analysed for their $S_{6}, S_{7}$ and $S_{8}$ content via HPLC both before and after filtration. In this analysis only the UV element was used as a detector and integration was not performed. Methanol was used as the mobile phase with a flow rate of $1.6 \mathrm{~m} 1 / \mathrm{min}$. The sulfur samples were warmed prior to filtration.

The finely divided cadmium is produced by reacting $1 \mathrm{M}$ $\mathrm{Cd}\left(\mathrm{NO}_{3}\right)_{2}$ in water with three times the stoichiometric amount of $\mathrm{NaBH}_{4}$ to ensure complete reduction. The mixture is rinsed with water and dilute acid to remove any unreacted $\mathrm{NaBH}_{4}$, rinsed with water again and finally with DMSO .

\section{Electrochemistry of Bulk Sulfur}

Two experiments were performed on bulk sulfur. One was to determine diffusion limited sulfur currents under similar conditions as for a CdS deposition. As such the same cell and electrodes were used as for the deposits except that a solution of $10 \mathrm{mM} \mathrm{S}$ and 0.01 in $\mathrm{NaBF}_{4}$ in DMSO was used without any cadmium salts. Background currents using just 
$0.10 \mathrm{M} \mathrm{NaBF}_{4}$ in DMSO were also measured and subtracted from the sulfur curves. These voltammetric measurements were made using the potentiostat at scan rates of $200 \mathrm{mV} / \mathrm{s}$. These currents were measured for temperatures ranging from $60^{\circ}$ to $110^{\circ}$ at $10^{\circ}$ intervals.

The other bulk sulfur measurements were made in acetonitrile with the thin layer flow cell (TLFC). Sulfur concentration was $0.100 \mathrm{~g} / 1$ with $0.100 \mathrm{M} \mathrm{NaClO}_{4}$ as electrolyte. The working electrode was gold with a glassy carbon counter electrode and a silver/silver chloride reference electrode. Solutions were deoxygenated.

$\underline{S}_{6}, \underline{S}_{7}$ and $\underline{S}_{8}$ Electrochemistry using High Pressure Liquid Chromatography

$\mathrm{S}_{6}, \mathrm{~S}_{7}$ and $\mathrm{S}_{8}$ were analyzed electrochemically by separating them with HPLC, quantitating them with the UV detector and measuring them with an electrochemical flow cell. Sulfur samples were dissolved in methanol or acetonitrile and kept near the boiling point of the solvent to ensure maximum $S_{6}$ and $S_{7}$ concentrations.

Equipment configuration for the bipotentiostat arrangement is shown in figure 2. The equipment set up is similar when the regular potentiostat is used, except that there is only one working electrode and current output. Electrochemical flow cells used were the thin layer flow cell (TLFC) and a porous carbon coulometric flow cell 


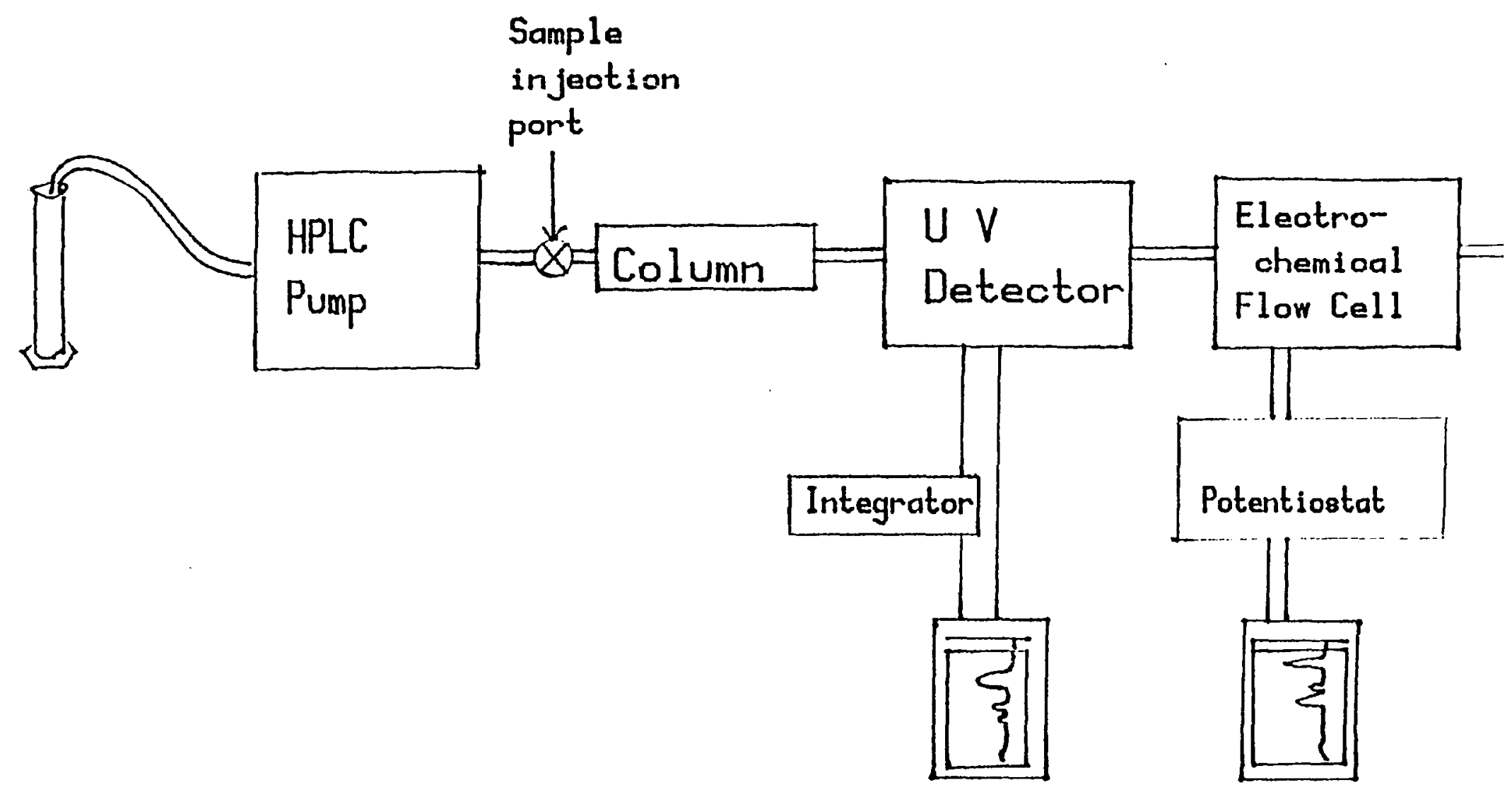

Chart Recorders

Figure 2. Configuration of equipment used for electrochemical measurements of sulfur spectes. 
assembled here at Portland State University. This latter flow cell used porous carbon electrodes manufactured at Environmental Sciences Associates for their Model 5100 LC Detector; the counter electrode used was zinc to reduce plating on the porous carbon and minimize interaction with the sulfur. Its potential was monitored with a Ag/AgCl electrode.

In the presence of oxygen the sulfur reduction is impossible to observe. Thus the eluant was bubbled with nitrogen or argon for at least one hour and then the HPLC machine was flushed with this deoxygenated solvent for another hour. The solvents were liquid chromatography grade. Acetonitrile came from Burdick \& Jackson, Baker, or Mallinckrodt. Methanol was from Burdick \& Jackson, Baker, or E. M. Science.

At the start of each of these experiments, the electrodes give irreproducible results. Only after conditioning by repeated exposure to sulfur would results and baselines stabilize. To facilitate this stabilization, electrodes were often flushed with straight sulfur solution, bypassing the column and UV detector.

For each of these measurements, the potential and the flow rate is fixed. But both of these variables can and were changed between runs. Other important parameters that remained fixed are as follows: UV detector wavelength $=254$ $\mathrm{nm}$, UV detector volume $=12.5$ microliters, time constant of 
UV integrator $=1$ second, volume of sample loop $=20$ microliters.

Sulfur Reduction on Gold. In the first of these experiments, sulfur was reduced in the TLFC at differing potentials but constant flow rate. Current peak heights were normalized against absorbance peak heights and no integrations were performed. $0.050 \quad M$ tetraethylammonium perchlorate (TEAP, Southwestern Analytical Chemicals) in methanol was used as the eluant. The sample was $0.300 \mathrm{~g} / 1$ of sulfur in methanol.

Kinetic Effects of Sulfur on Gold. In these experiments the charge (integrated current) and the current peak heights were measured at different flow rates at various potentials. The charge and current measurements were normalized against their integrated absorbance and current peaks at each flow rate were also normalized against the corresponding peak of the reversible system hydroquinone at the same flow rate. Also studied were some of the conditioning effects. This was dont by timing injections so that an $S_{8}$ peak would come just before the peak being studied.

$0.10 \mathrm{M} \mathrm{NaClO}_{4}$ in aceconitrile was the eluant and the sample was $0.100 \mathrm{~g} / 1$ of sulfur also in acetonitrile.

The hydroquinone normalizing peaks were made with $0.2 \%$ $\mathrm{v} / \mathrm{v} \mathrm{H}_{3} \mathrm{PO}_{4}$ in $1: 5 \mathrm{v} / \mathrm{v}$ methanol:water as the mobile phase. This solution was also used to make the sample of 10 
micrograms/liter hydroquinone.

Sulfur Reduction in Porous $\underline{\text { Carbon. For these }}$ measurements different flow rates were used at potentials near -1.0 volt vs. Ag/AgCl. The eluant was $0.10 \mathrm{M} \mathrm{NaClO}_{4}$ in acetonitrile and the sample was $0.100 \mathrm{~g} / 1$ of sulfur in acetonitrile.

Sulfur Reduction on Cadmium Sulfide. A single crystal cadmium sulfide electrode with an ohmic contact was set in epoxy with the c-axis perpendicular to the surface. This piece was then machined to fit the LC-17 thin layer flow cel1. Thus a CdS thin layer flow cell was constructed with a glassy carbon counter electrode.

This cell was connected to the HPLC and sulfur species electrochemistry was performed at various potentials. A $0.100 \mathrm{~g} / 1 \mathrm{~S}_{8}$ in acetonitrile kept at $75^{\circ}$ and a $0.039 \mathrm{~g} / 1$ "S $7^{\prime \prime}$ in acetonitrile kept at $0^{\circ}$ were used as samples. Only one flow rate of $1.0 \mathrm{~m} 1 / \mathrm{min}$ was used.

$\underline{S}_{7}$ Experiments

Crude $\mathrm{S}_{7}$ was isolated from a sulfur melt by the technique described by Steudel and Maeusle (26). A saturated solution of this $\mathrm{S}_{7}$ in acetonitrile was made with a concentration of $39 \mathrm{mg} / \mathrm{L}$. It was diluted in half and a control sample of this solution was made and stored at $0^{\circ}$ in the dark. A UV spectra was recorded with a Beckman 26 Spectrophotometer, and the sample was then exposed over time at room temperature to a UVS-54 Mineralite Lamp (U1traviolet 
Products, Inc.). UV spectra were recorded at periodic intervals to follow the decomposition reaction. When this solution's spectrum no longer changed it was injected into the HPLC to analyse the amounts of components. The control sample was also injected to compare with the decomposed sample. The species distribution data from the control sample was also used to calculate the absorptivity constant of $\mathrm{S}_{7}$ at $254 \mathrm{~nm}$ by calculating the amounts of the other species, substracting this mass from the total sulfur mass, and using the difference in the final calculation.

\section{Electrochemical Photocapacitance Spectra}

Several CdS deposits were made on different substrates including gold and cadmium metal. The deposition conditions were $0.20 \mathrm{~F} \mathrm{CdCl}_{2}, 0.10 \mathrm{~F} \mathrm{~S}, 2 \times 10^{-8} \mathrm{BiCl}_{3}, 0.10 \mathrm{~F} \mathrm{NaBF}_{4}$, $90^{\circ} \mathrm{C}$ and $0.30 \mathrm{~mA} / \mathrm{cm}^{2}$. A bismuth sulfide deposit on cadmium metal was also made under the same conditions except that the $\mathrm{BiCl}_{3}$ concentration was $0.20 \mathrm{mF}$. Other conditions are as described previously. Electrochemical photocapacitance spectra were recorded by Ron Haak at the Rockwell Science Center in Thousand Oaks, California. 
CHAPTER III

\section{RESULTS}

Deposition Conditions for CdS

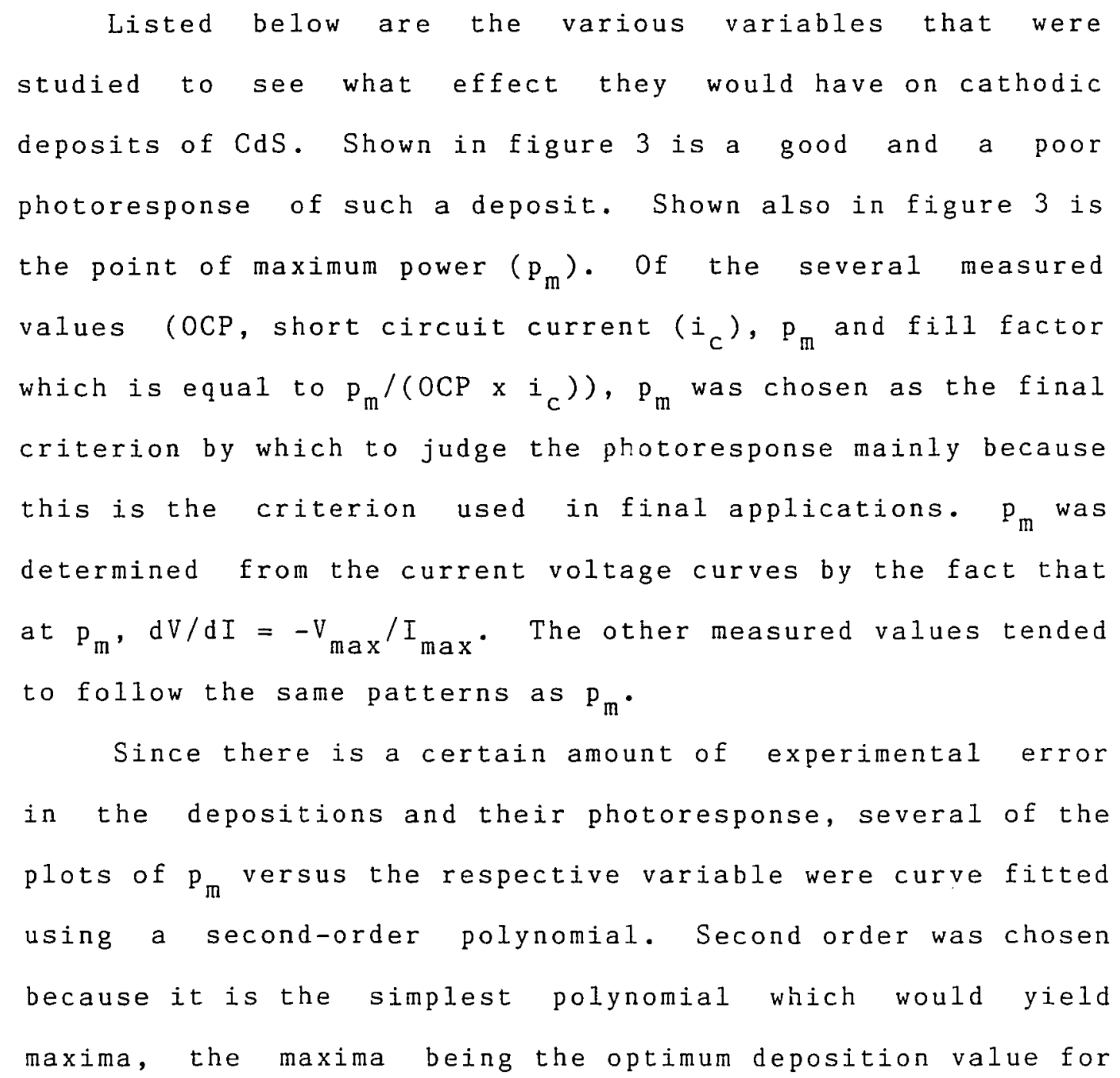



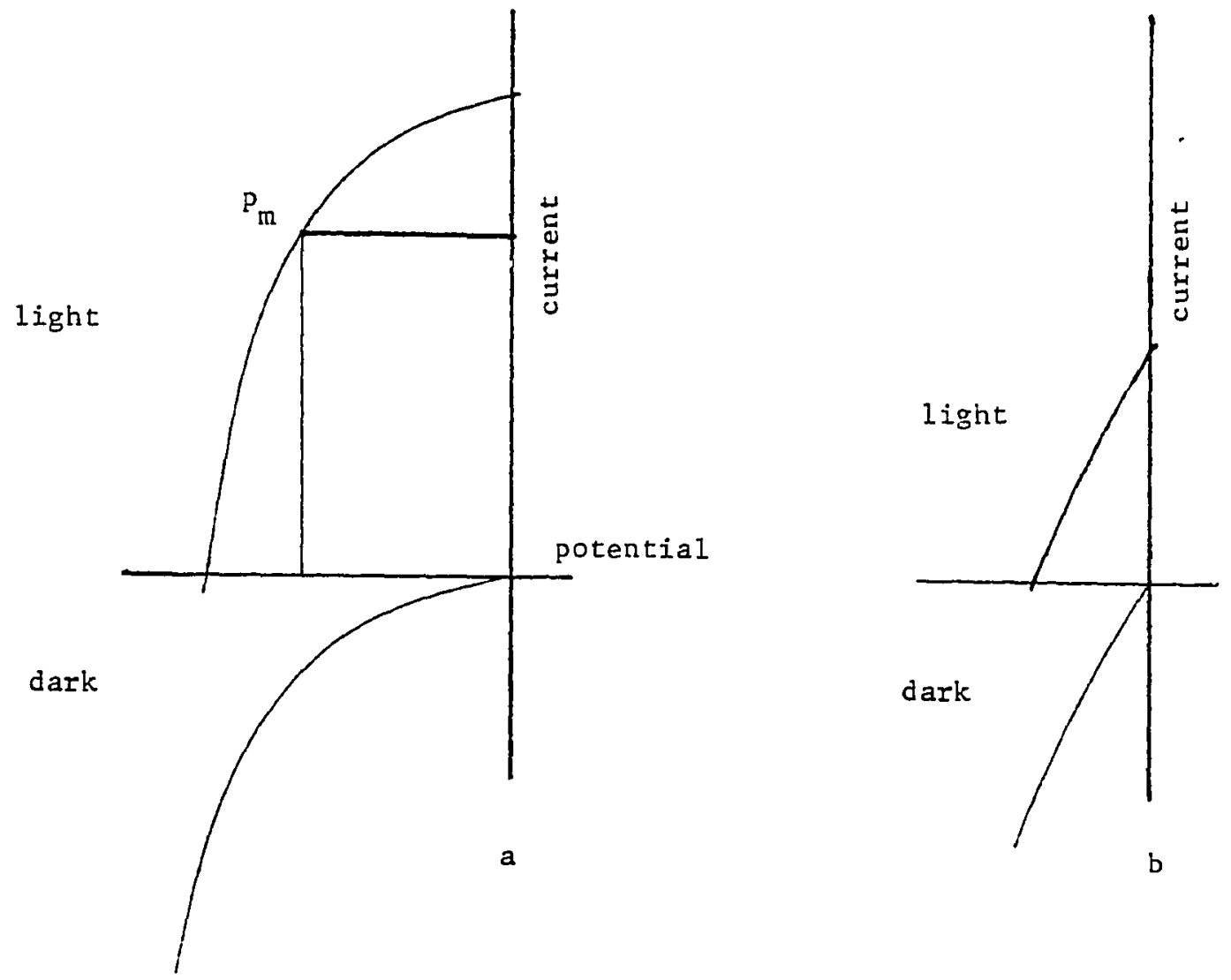

b

Figure 3. Typical results of a photoresponse test of cas. a) a current-voltage curve for a Cas deposit with a good photoresponse. Also shown is the point of maximum power. b) as in (a) except with a poor photoresponse. Note the decreased curvature, as well as the smaller currents and potentials. 
that variadle.

Temperature. The first set of temperature studies from $60^{\circ}$ to $130^{\circ}$ showed the ideal temperature to be $90^{\circ}$. See figure 4 for more detailed results. The second set of measurements was taken in the range of $81^{\circ}$ to $99^{\circ}$ and showed that the optimal temperature is $88 \pm 3^{\circ} \mathrm{C}$.

Also measured as a function of temperature was the diffusion limiting currents due to $\mathrm{S}_{8}$ in a DMSO solution under our stirring conditions. The results are shown in figure 5 and was used to set an upper limit for the current density.

Current Density. The measurements taken with varying current densities agree that the ideal current density region is 0.20 to $0.30 \mathrm{~mA} / \mathrm{cm}^{2}$. See figure 6. Deposits made below $0.17 \mathrm{~mA} / \mathrm{cm}^{2}$ were generally poor. The change at 0.17 $\mathrm{mA} / \mathrm{cm}^{2}$ was quite sharp relative to the gradual tapering off at current densities higher than $0.30 \mathrm{~mA} / \mathrm{cm}^{2}$.

Sulfur Concentration. The optimum sulfur concentration appears to be near $0.1 \mathrm{M}$ of sulfur atoms. See figure 7 . This just below the concentration of sulfur at saturation, 0.19 M. All of these deposits, and those for the cadmium concentration studies too, were made at $90^{\circ} \mathrm{C}$ with current densities near $0.30 \mathrm{~mA} / \mathrm{cm}^{2}$.

Cadmium Concentration. For the effect of cadmium ion concentration of photopower see figure 8 . The best deposits occurred at $0.20 \mathrm{M} \mathrm{CdCl}_{2}$. 

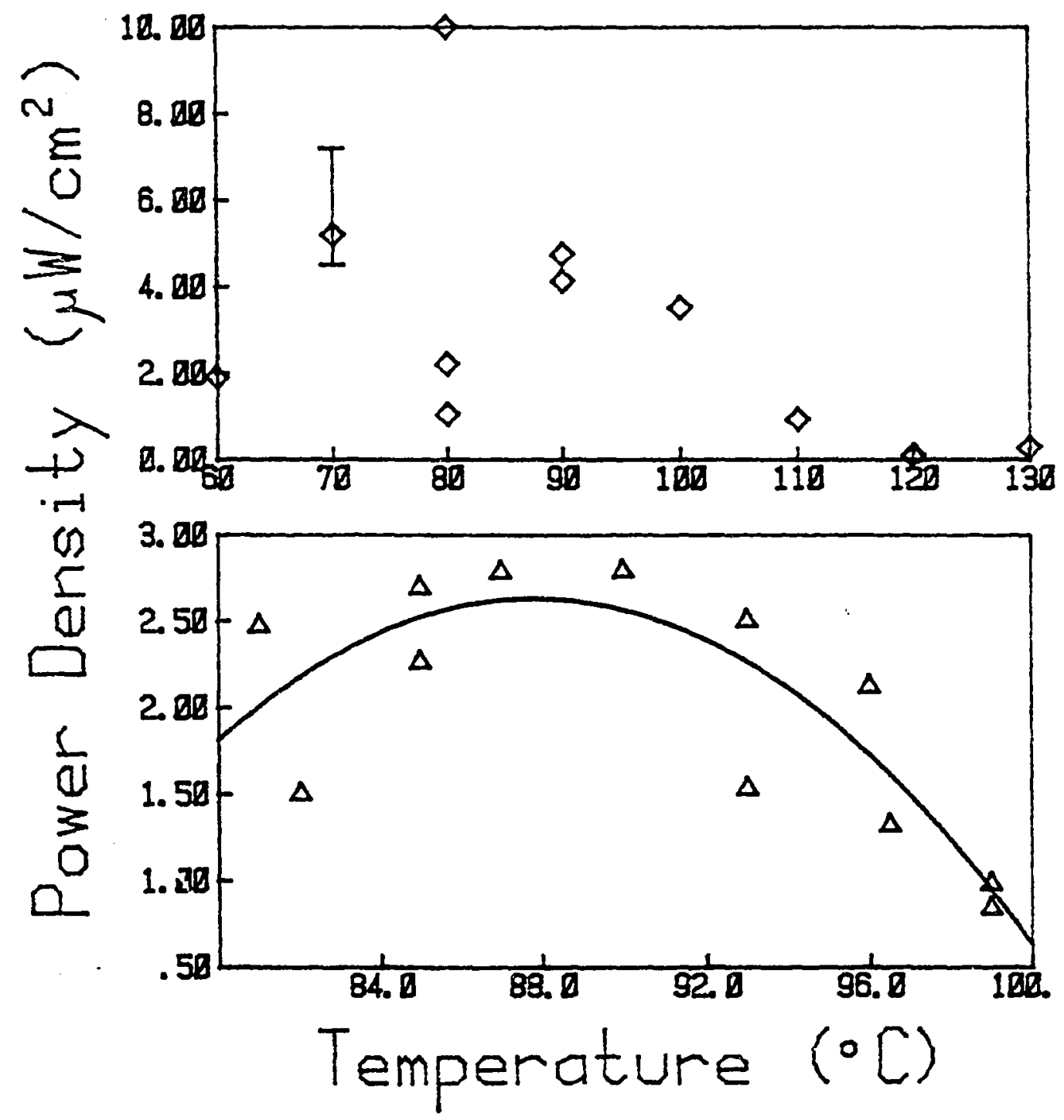

Figure 4. Photoresponse of CdS deposits as a function of temperature. 


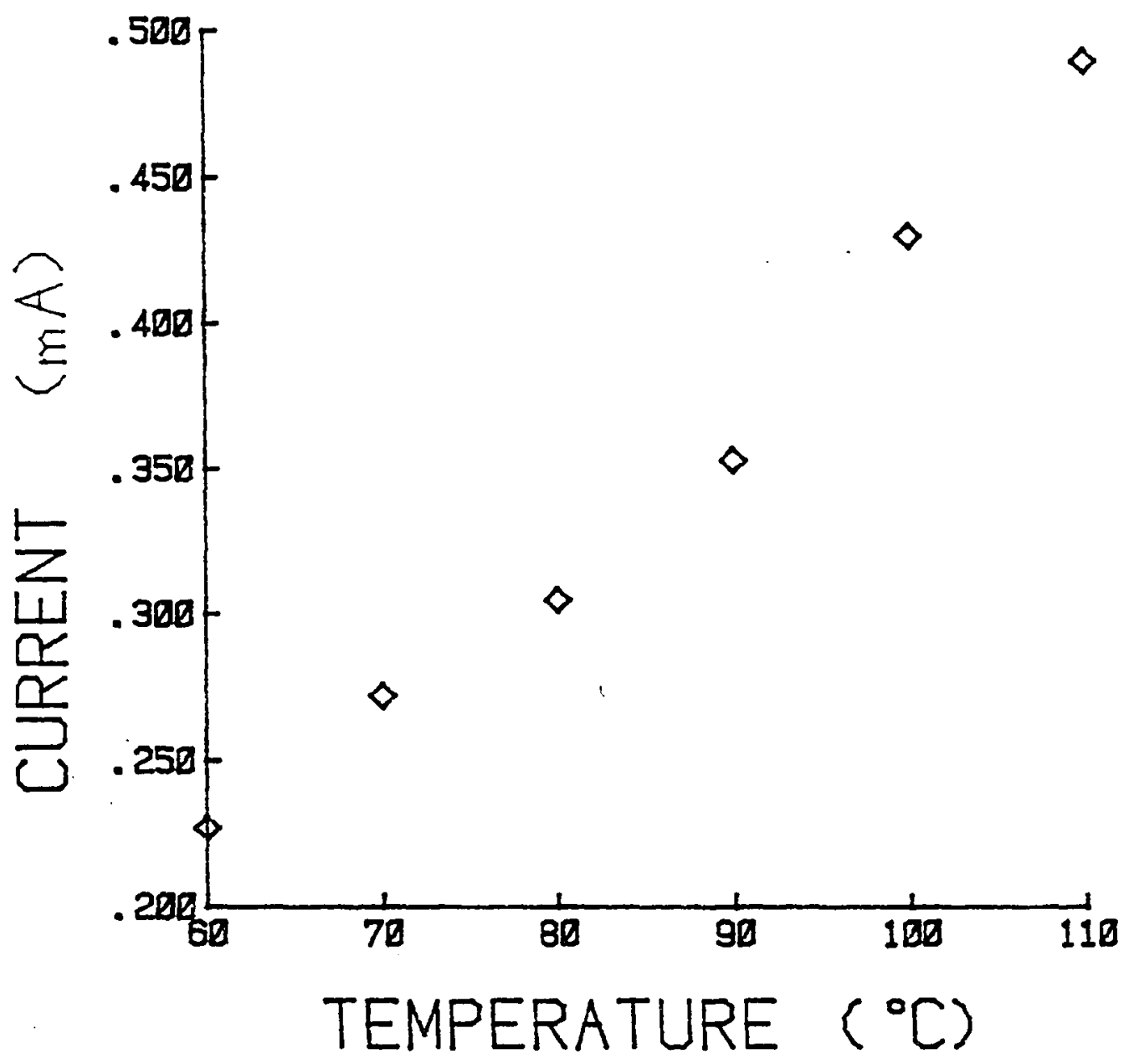

Figure 5. Iimiting current of sulfur as a function of temperature.. Surface area of the electrode, $1.7 \mathrm{~cm}^{2}$. Concentration of $\mathrm{S}_{8}, 1.25 \mathrm{M}$. 


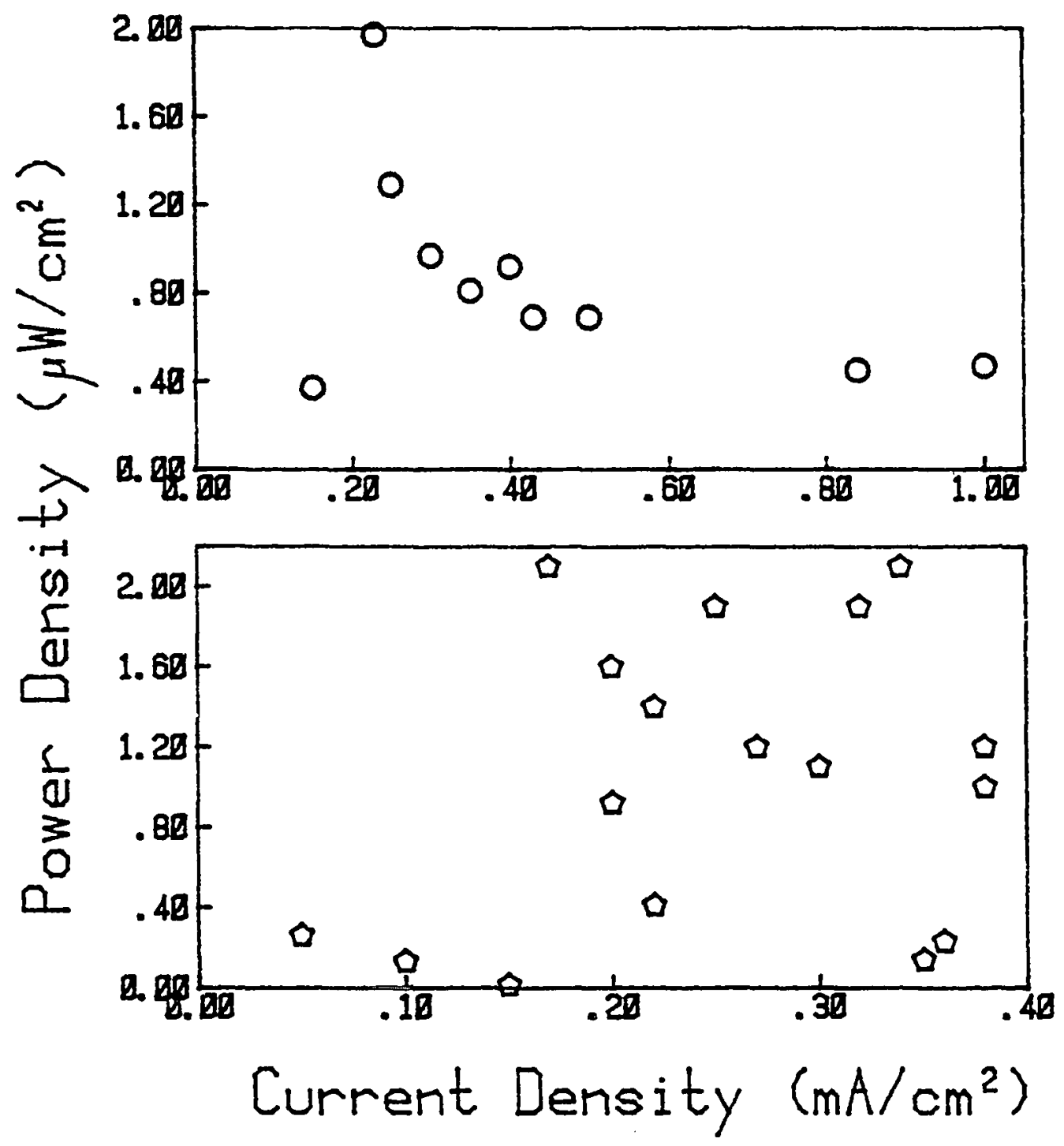

Figure 6. Photoresponse of CdS deposits as a function of deposition current density. $0-0.05 \mathrm{~F} \mathrm{CdCl} 2,0.10 \mathrm{~F} \mathrm{~S}$

$\Delta-5 \mathrm{mFCaCl} 2, .10 \mathrm{mF} S$ 


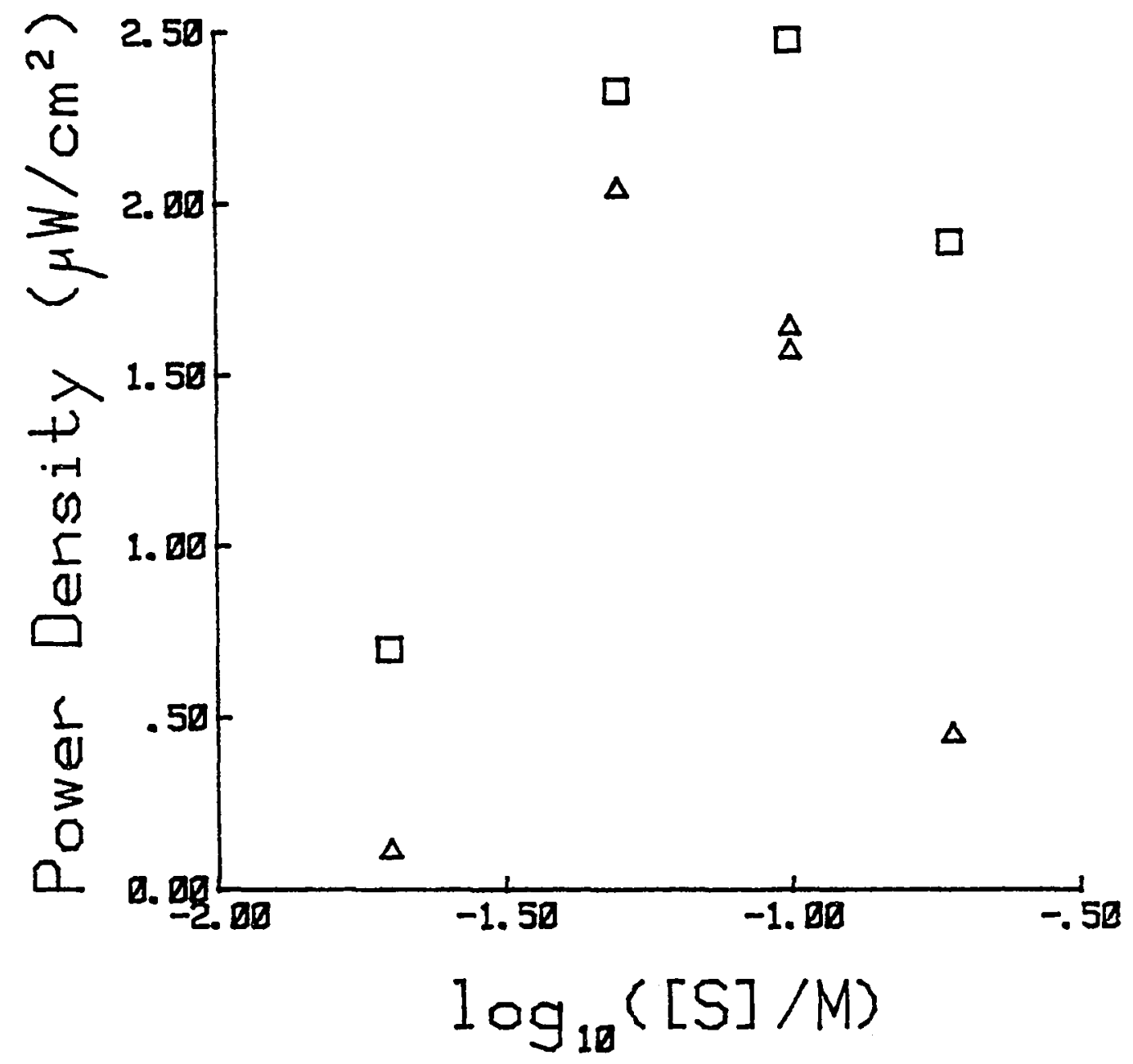

Figure 2. Photoresponse of cas deposits as a function of sulfur concentration in the deposition solution. Other deposition conditions were $90^{\circ}, .3 \mathrm{~mA} / \mathrm{cm}^{2}, 0.10 \mathrm{~F} \mathrm{NaBF} 4,50 \mathrm{mF} \mathrm{CdCl} 2$ for $\square$, and $20 \mathrm{mF} \mathrm{CdCl}_{2}$ for $\Delta$. 


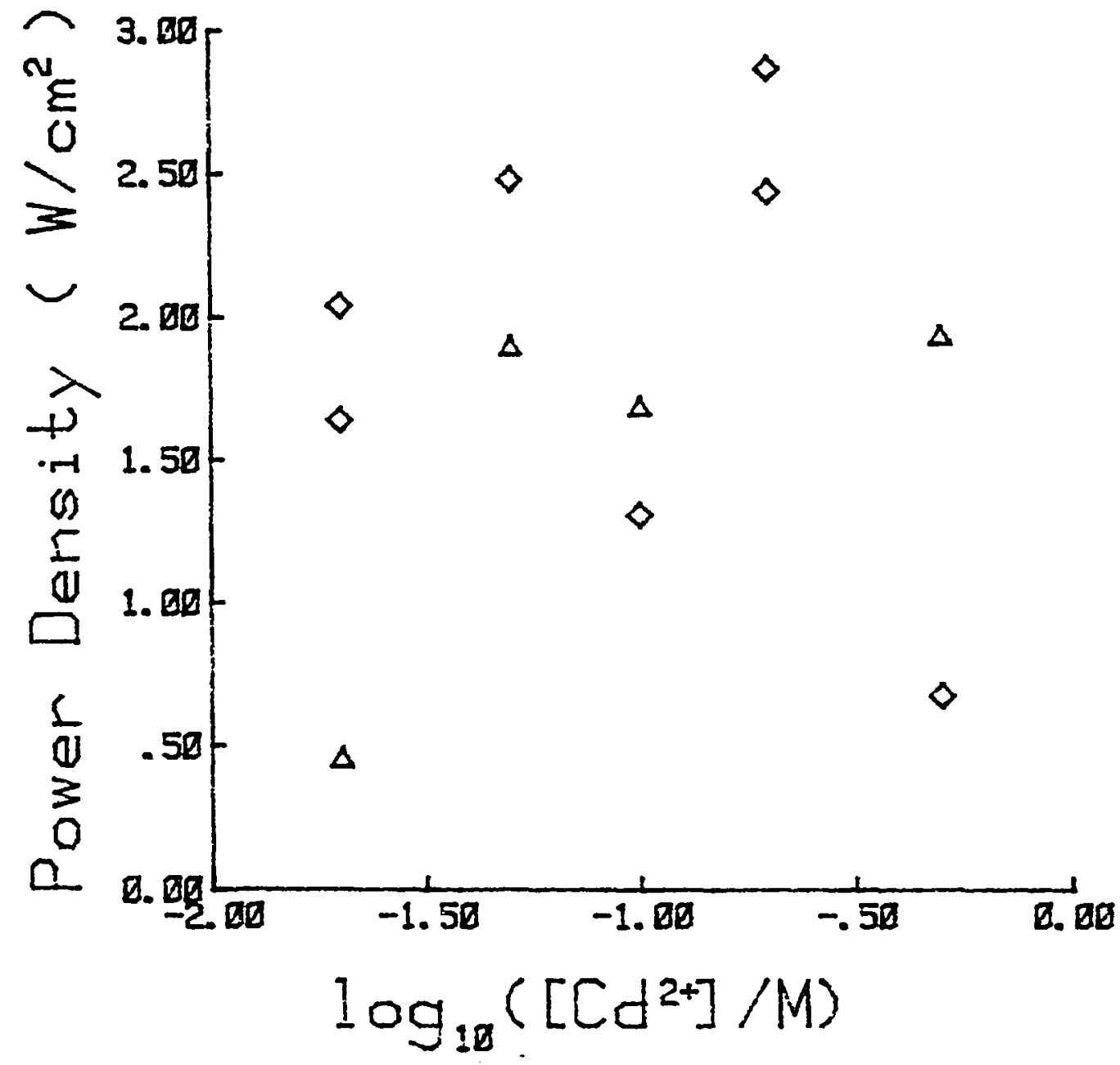

Figure 8. Photoresponse of CdS deposits verses cadmium concentration in the deposition solution. The deposition conditions were $90^{\circ}, 0.3 \mathrm{~mA} / \mathrm{cm}^{2}$, $0.10 \mathrm{~F} \mathrm{NaBF}_{4}, 0.10 \mathrm{~F} \mathrm{~S}$ for $\diamond$ and $0.19 \mathrm{~F} \mathrm{~S}$ for $\Delta$. 
Doping with Bismuth Ion. At a $\left[\mathrm{Bi}^{3+}\right] /\left[\mathrm{Cd}^{2+}\right]$ ratio of $10^{-3}$ the cathodic deposits gave a thin film of a coherent very dark green, almost black substance. These films had unexpected1y high photocurrents and it is most probable that these deposits were mainly $\mathrm{Bi}_{2} \mathrm{~S}_{3}$ rather than CdS.

At lower bismuth ion ratios the more cypical orange colored deposits of CdS appeared. The best doping level occurred near a $\left[\mathrm{Bi}^{3+}\right] /\left[\mathrm{Cd}^{2+}\right]$ ratio of $10^{-7}$. For the results of this experiment see figure 9. Another very important effect of this doping is that it greatly reduced the noise that had been seen in previous experiments.

Filtration of Sulfur through Cadmium Metal

Sulfur solutions in DMSO were filtered through finely divided cadmium metal. The solutions were measured for $\mathrm{S}_{6}$, $\mathrm{S}_{7}$ and $\mathrm{S}_{8}$ concentration before and after each filtration by HPLC .

Multiple filtrations were made through the same cadmium. At room temperature $S_{6}, S_{7}$ and $S_{8}$ are removed in equal proportions, but in subsequent filtrations, the metal becomes passivated with either elemental sulfur or CdS. At $90^{\circ} \mathrm{S}_{7}$ is much more reactive; $34 \pm 5 \%$ of $\mathrm{S}_{7}$ is removed while $17 \pm 4 \%$ and $19 \pm 2 \%$ of $S_{6}$ and $S_{8}$ respectively are removed. Subsequent filtrations also tended to passivate but not as strongly as at room temperature. 


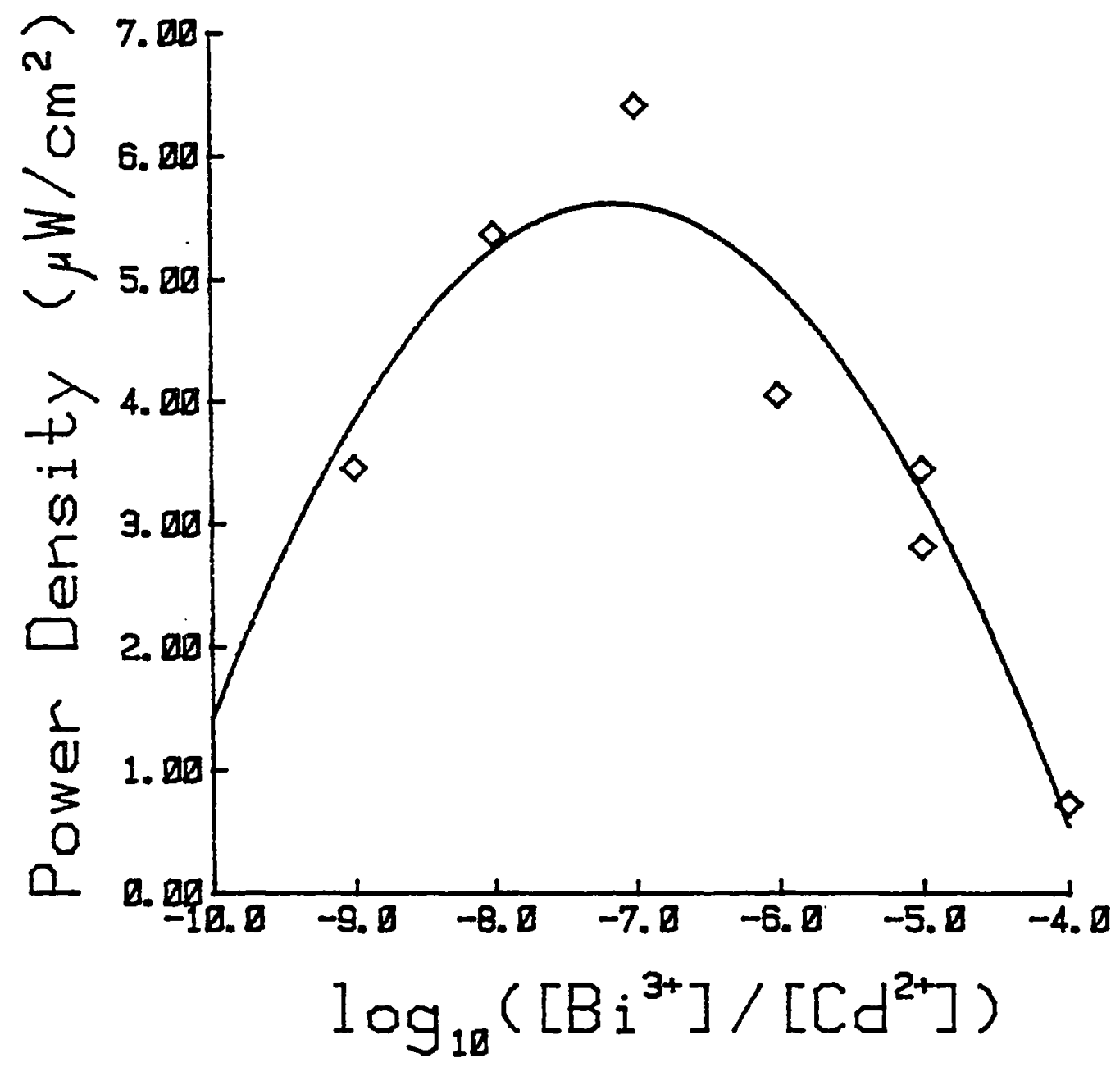

Figure 2. Photoresponse of cas depposits yerses the logarithm of the ratio or $\mathrm{Bi}^{+3}$ to $\mathrm{Cd}^{+2}$ ions in the deposition solution. 


\section{Electrochemistry of Sulfur Species}

Given below are the results of several different electrochemical studies of sulfur. Most of these studies involve the individual sulfur species $S_{6}, S_{7}$ and $S_{8}$ which were separated and analysed by HLPC. Initial studies were made in methanol but subsequent studies were made in acetonitrile to eliminate proton effects(22). All potentials are versus an aqueous silver-silver chloride electrode. The presence of oxygen would cause a large background current. When the sulfur species would come through the electrode in the presence of oxygen, there would appear to be an anode wave which was actually a diminishing of the oxygen reduction. Thus it is very important for these measurements to eliminate oxygen as much as possible.

Sulfur Species on Gold Electrodes. In the first of these experiments the sulfur species were dissolved in methanol, separated by HPLC, detected by a UV detector and reduced on a gold electrode which was at a fixed potential. This potential was varied between $r$ uns and by normalizing the measured current peaks against the absorbance peaks it was possible to establish the current voltage curves shown in figure 10. Using the diffusion limiting currents from the plateau region of these curves it was possible to make Tafel plots of these sulfur reductions which gave half wave reductions and Tafel slopes. The half wave potentials of 


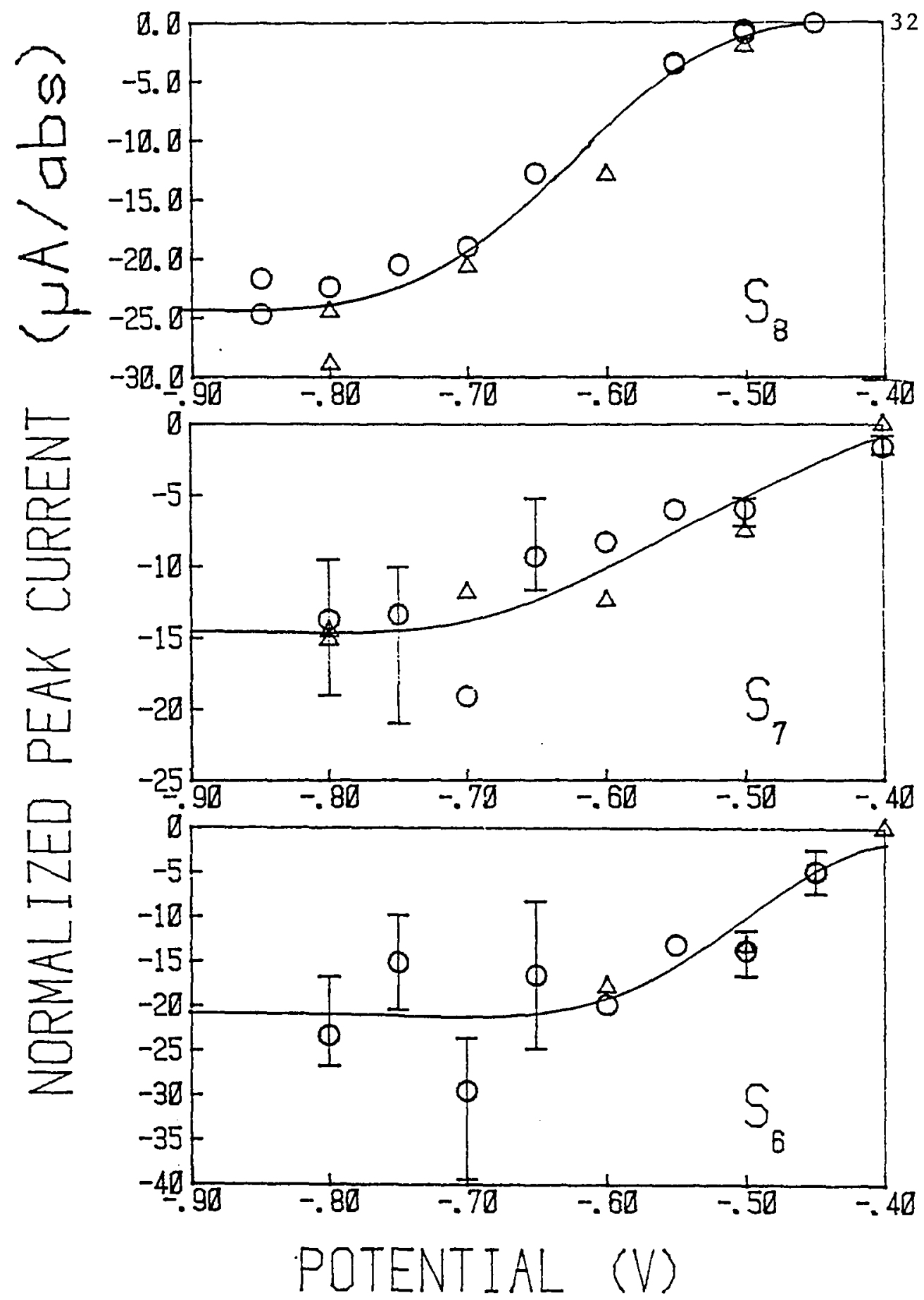

Flgure 10. Peak current of sulfur species reduction on a gold electrode verses potential. Peaks are normalized against the absorbance peaks from the HPLC detector. Error bars are due to baseline changes before and after the current peak. 
$\mathrm{S}_{6}, \mathrm{~S}_{7}$ and $\mathrm{S}_{8}$ were respective1y $-0.50 \pm 0.03 \mathrm{~V}, \quad-0.54 \pm 0.03 \mathrm{~V}$, and $-0.63 \pm 0.02 \mathrm{~V}$ indicating that $\mathrm{S}_{6}$ and $\mathrm{S}_{7}$ are indeed more electrochemically active than $S_{8}$. Tafel slopes of all three species were very nearly the same at $0.042 \mathrm{~V}$ which indicates that all three are reduced irreversibly.

Also noted for this gold electrode was a conditioning effect. Initial results were not reproducible but by repeated exposure of the electrode to the sulfur the electrode would stabilize. This conditioning of the electrode was studied in acetonitrile to eliminate proton effects. This conditioning could be achieved by repeated injections of sulfur samples through the HPLC but a much quicker conditioning could be achieved by injecting a sulfur solution directly into the electrochemical flow cell.

This effect could be further studied by making multiple injections through the HPLC and timing the injections so that the large $S_{8}$ peak would come immediately before the $S_{x}$ (or other species) peak being studied. For $\mathrm{x}=6,7$, or 8 , $\mathrm{S} x$ peaks that came immediately after an $S_{8}$ peak were diminished and conversely peaks that came more than a minute after the $\mathrm{S}_{8}$ peak were enhanced. Still, all of these peaks were larger than the peaks observed prior to any conditioning, i.e. the initial injections. Thus the prior history of the gold electrode's exposure to sulfur affects its response.

Flow rate studies were also made on this gold electrode after conditioning. The UV detectors absorbance signal was 
integrated so that the total amount of each sulfur species could be calculated. Flow rates of $0.5,1.0$ and $2.0 \mathrm{ml} / \mathrm{min}$ were used. Current peaks were normalized against both the amount of the sulfur species detected by UV and also the peak height at the respective flow rates for the reversible system quinone/hydroquinone. The former normalization accounts for concentration variation among samples. The later normalization accounts for differing spreading of the peak widths at differing flow rates for this particular HPLC and flow cell geometries. Results are shown in figure 11 at various potentials. Note that in almost every case there is a decrease in the peak current at $0.5 \mathrm{ml} / \mathrm{min}$. Also the $\mathrm{S}_{7}$ peak currents at $1.0 \mathrm{ml} / \mathrm{min}$ are depressed relative to 2.0 $\mathrm{m} 1 / \mathrm{min}$.

Sulfur Species on Porous Carbon Electrodes. Porous carbon electrodes with near coulometric efficiency were constructed with zinc counter electrodes in flow cells and connected to the HPLC. Absorbance, integrated absorbance, current and integrated current (charge) were all measured as the sulfur species passed out of the HPLC column. It was noted that different amounts of charge were consumed per mole at different flow rates. Results are shown in figure 12. It is shown here that $\mathrm{S}_{8}$ is reduced by two electrons per mole at higher flow rates but is reduced by eleven electrons per mole at low flow rates. $S_{7}$ is reduced by twelve electrons per mole at higher flow rates and seven 


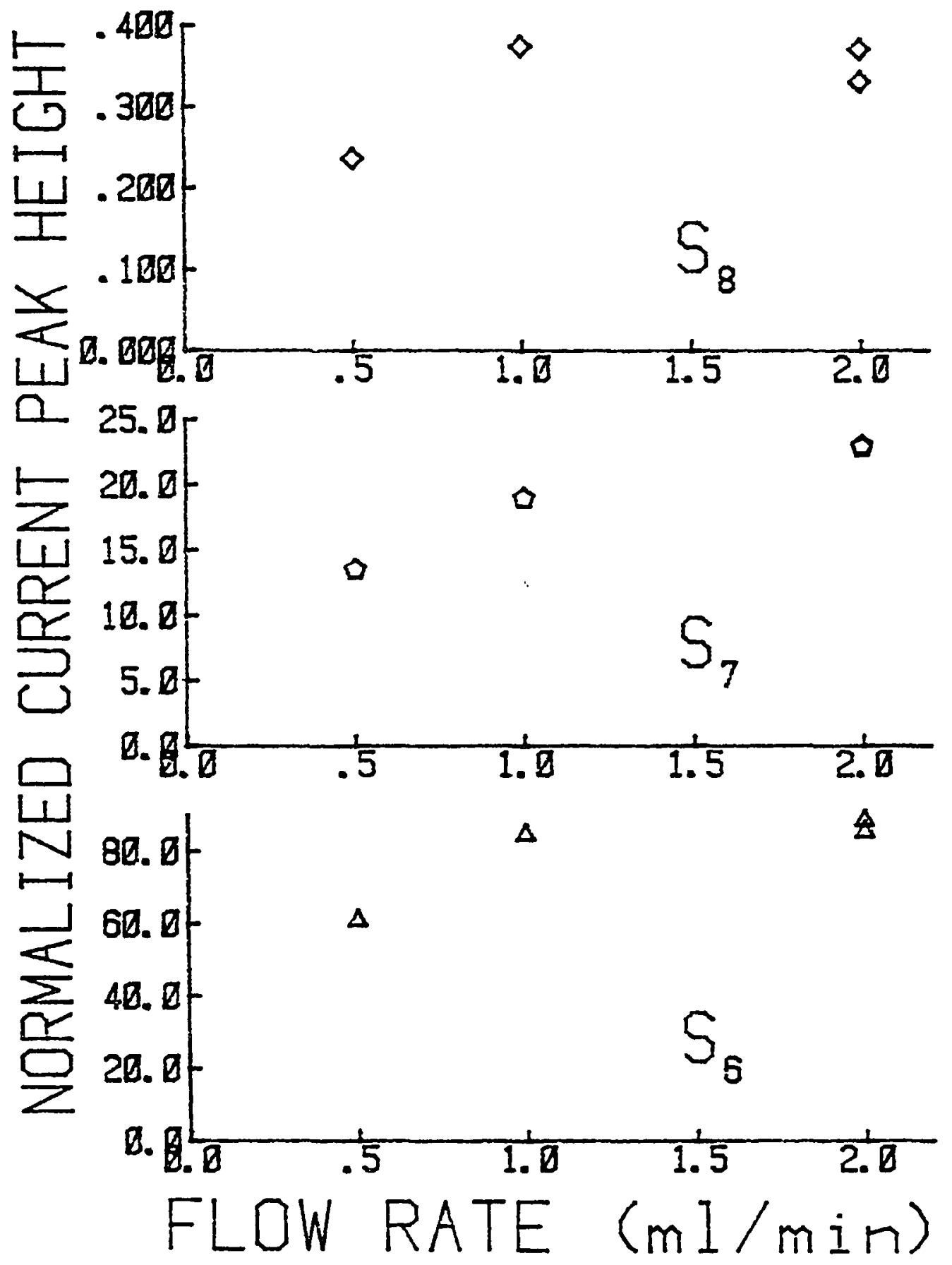

Figure 11. Peak currents of sulfur reduction on a gold flow cell electrode at $-.70 \mathrm{~V}$ verses flow rate through the cell. See text for the normalizing procedure. 


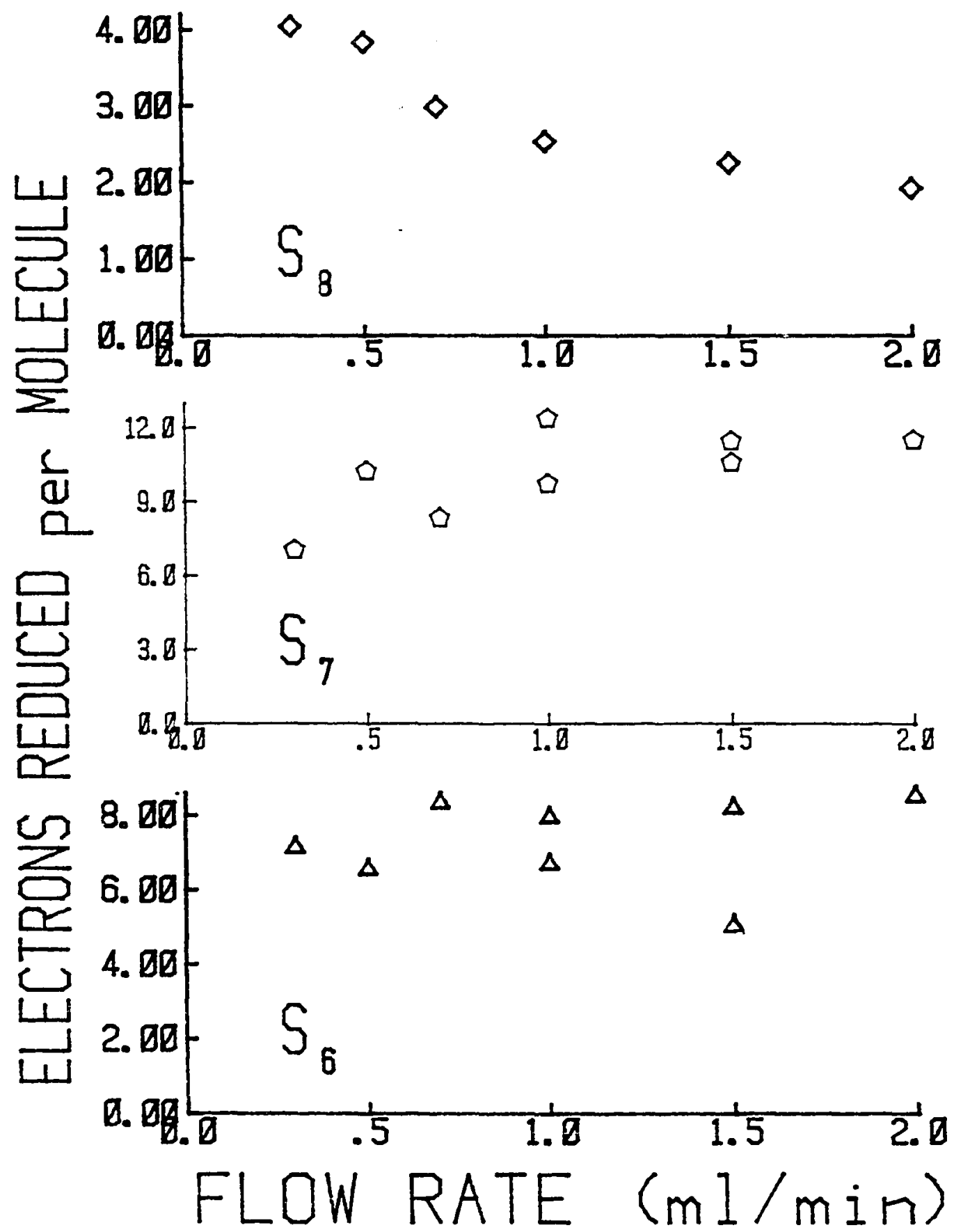

Figure 12. The average number of electrons reduced per sulfur molecule on a porous carbon electrode verses flow rate of solvent through the electrode. 
electrons per molecule at lower flow rates but this may be due to the decomposition in the UV detector of the UV sensitive $S_{7}$ to form $S_{8} \cdot S_{6}$ reduction is more noisy due to its smaller signal but its reduction is fairly constant over the whole spectrum of flow rates with an average value of eight electrons per molecule. Thus near this potential $(-1.0 \mathrm{~V}) \mathrm{S}_{6}$ and $\mathrm{S}_{7}$ are reduced more completely than $\mathrm{S}_{8}$.

Sulfur Reduction on a Cadmium Sulfide Electrode. In these experiments both $S_{8}$ and $S_{7}$ samples dissolved in acetonitrile were pumped through the HPLC column and a thin layer cell with a cadmium sulfide electrode. There was a conditioning effect as seen on the other electrodes but the resultant current peaks took on an unusual shape. When the $S_{8}$ species came through the eletrode, two peaks appeared. See figure 13. The first peak was sharp and attributable to the bulk $\mathrm{S}_{8}$ species passing through the electrode. The second peak was broader and appears after the bulk of $\mathrm{S}_{8}$ has passed. This second peak also diminished more than the first peak at lower potentials.

The above description applies to the $\mathrm{S}_{8}$ samples. When $\mathrm{S}_{7}$ samples were passed through the system, a similar double peak was seen for $S_{7}$ rather than the minor constituent $S_{8}$. Thus for both $S_{7}$ and $S_{8}$ samples, the major constituent gave double peaks while the minor constituents gave the usual single peaks.

$\underline{S}_{7} \underline{\text { Chemistry }}$ 

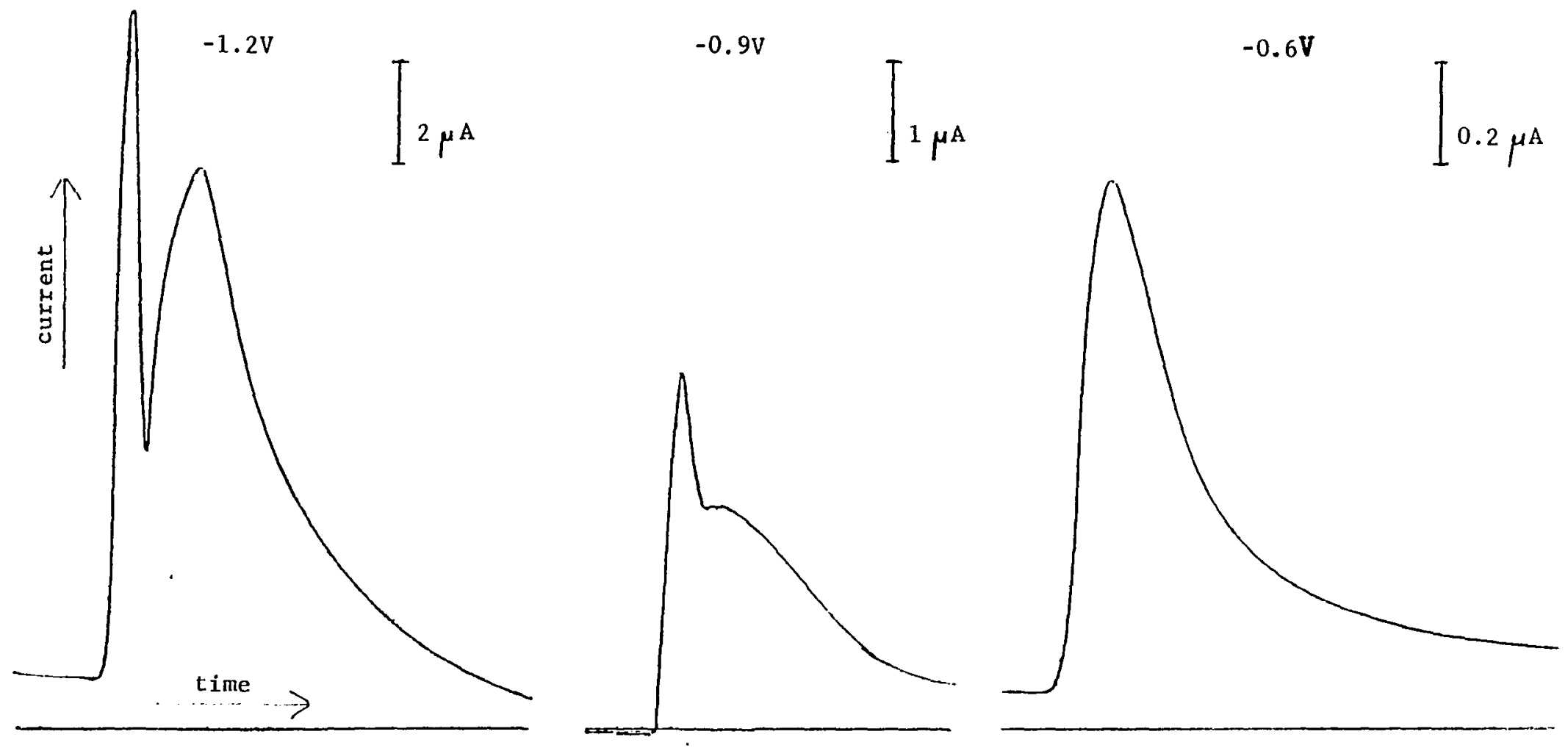

Figure 13. Current peaks due to $S_{8}$ reduction on a thin layer flow cell (potentials vs. $\mathrm{Ag} / \mathrm{AgCl}(\mathrm{aq})$ ). 
Crude $\mathrm{S}_{7}$ was isolated from a sulfur melt. The molar absorptivity was calculated as follows. A dilute solution in acetonitrile was made but the sample would not all dissolve. This solution was gravimetrically filtered and this mass of undissolved particles was substracted from the mass of the added sample to give the net dissolved mass. This solution was injected into the HPLC and the integrated absorbance at $254 \mathrm{~nm}$ was measured for all of the sulfur species present. The mass of $\mathrm{S}_{8}$ and $\mathrm{S}_{6}$ in these HPLC samples was calculated using the integrated adsorbance and their molar absorptivities which are 5930 (18) and 3130 (23) respectively. The HPLC masses of the larger sulfur rings were also estimated by this technique assuming that they had the same absorptivity per atom as $S_{8}$. The HPLC masses of all these sulfur species were then subtracted from the net dissolved mass of sulfur in the HPLC sample giving the nominal $S_{7}$ mass. This $S_{7}$ mass was then used to calculate the molar absorptivity which was $11,300 \pm 500$. The error in this number comes mainly from the net dissolved sulfur mass which was on $1 \mathrm{y} 3.9 \mathrm{mg}$ in $100 \mathrm{~m} 1$.

This large absorbance is confirmed by the decomposition studies that were made. In these tests, the same $\mathrm{S}_{7}$ sample in acetonitrile was photodecomposed by continuous exposure to a UV lamp (254 $\mathrm{nm})$. The changes in the sample were followed by periodically making a UV spectrum. Most of the changes occurred in the first few hours and a stable 
"equilibrium" had been reached by 18 hours. This stabilized solution was run through the HPLC which showed that $\mathrm{S}_{7}$ had decreased significantly, $S_{8}$ had increased only slightly while $S_{6}$ increased remarkably. Several larger sulfur rings also increased measurably, especially $S_{12} \cdot$ The reason that this confirms the large absorptivity calculated above is that for every decrease in absorbance for $S_{7}$ there was only half as much increase in absorbance for all the other species combined. 


\section{CHAPTER IV}

\section{ELECTROCHEMICAL PHOTOCAPACITANCE SPECTROSCOPY}

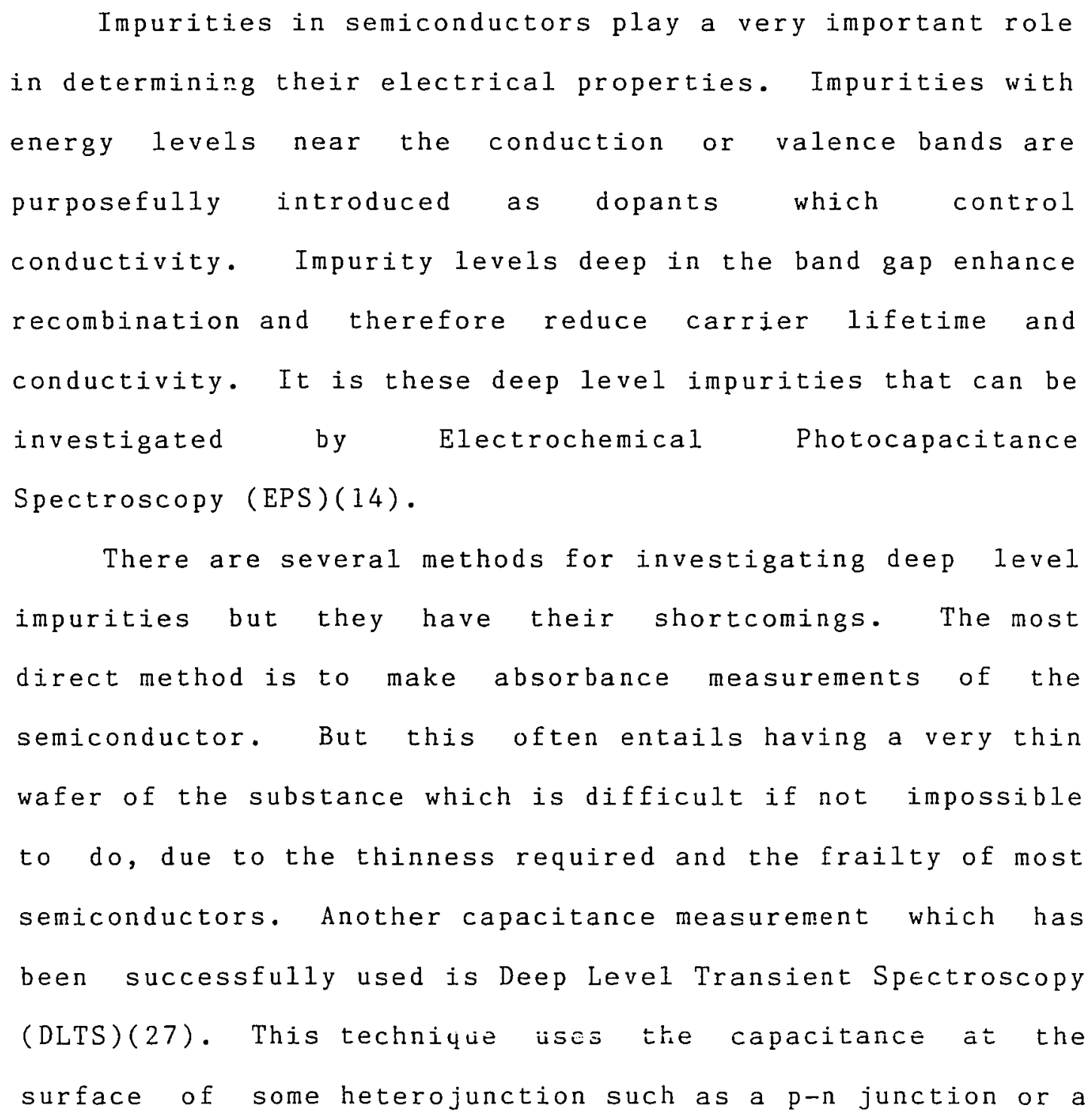


Schottky barrier. In this technique the transient capacitance of the junction is measured as a function of temperature. The shortcomings of this technique are the tedious and time consuming experimental work required, while the interpretation of the data is difficult and sometimes speculative. In contrast, EPS can be done on almost any semiconductor; the spectra can be measured in a few hours, and the interprotation is reasonably straightforward. In addition kinetic studies of these impurity levels are easily made.

EPS is similar to DLTS in that capacitance measurements are made at a heterojunction, but in the case of EPS the heterojunction is an electrolyte/semiconductor interface. A diagram of such a junction for an n-type semiconductor is shown in figure 14. This junction is reversed biased which causes charge to build up on the surface. Any donors that are thermally near the gap become ionized and their electrons (or holes in the case of a p-type semiconductor) are ionized into the conduction band and move down the potential gradient away from the surface of the semiconductor. This causes the charge on the surface to increase, and thus also the capacitance. When the spectrum is made, subband gap light is directed onto the semiconductor. This causes electrons trapped in impurity levels to be ionized by photon absorption, which causes the capacitance to increase. Similarly an electron could be 


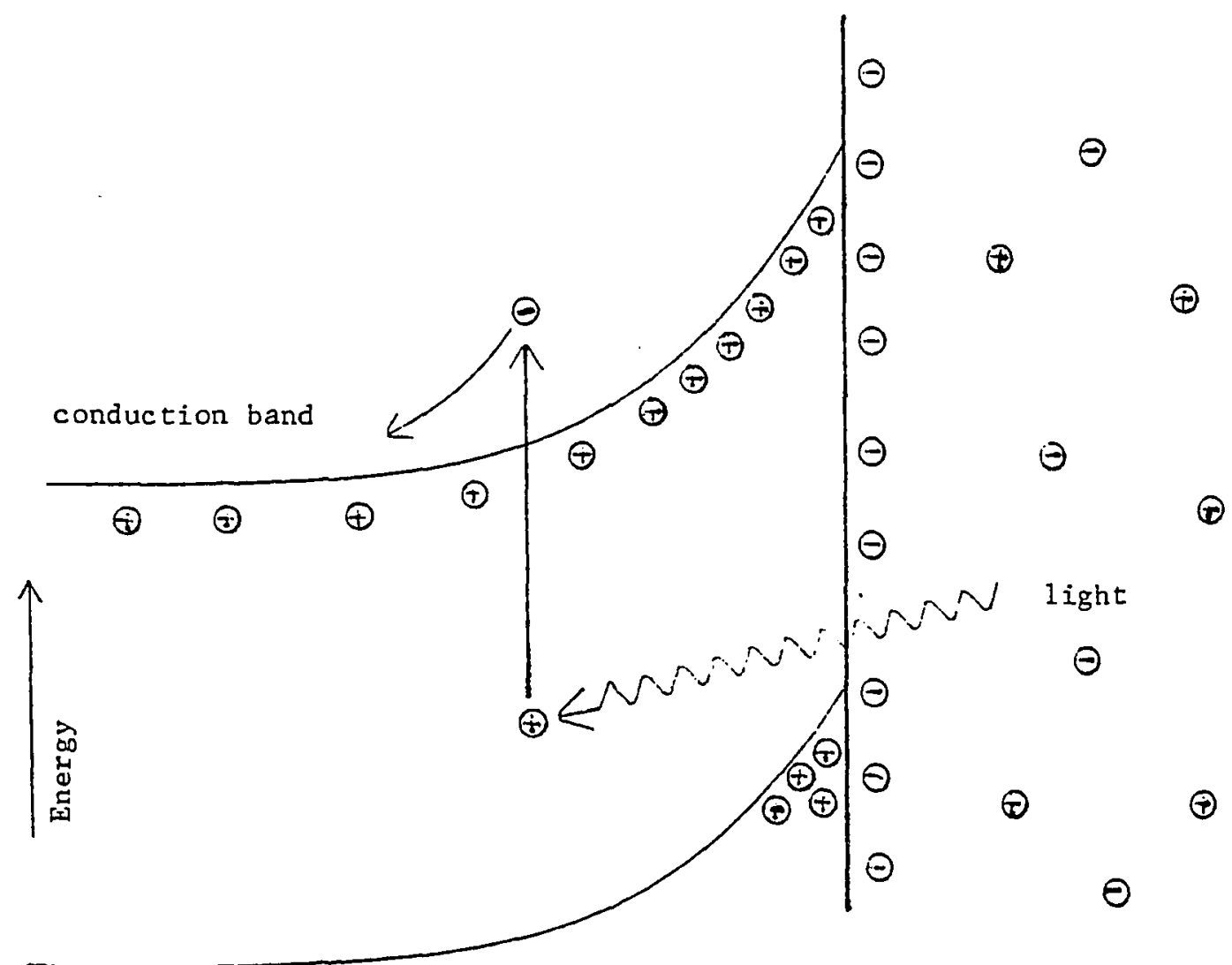

valence band

n-type semiconductor

electrolyte

Figure 14. Semiconductor electrolyte interface for EPS. Note the deep donor level from which a an electron can be photoexcited into the conduction band. 
ejected out of the valence band into an acceptor impurity, and this would cause a decrease in the capacitance. As the wavelength of the light is decreased more and more transitions occur which are monitored by the capacitance measurements. The plot of the capacitance versus wavelength gives the EPS results.

To analyse these photocapacitance spectra quantitatively it makes most sense to use the Mott-Schottky relationship (14):

$$
C_{d}^{2}=\epsilon \epsilon_{0} e N_{T} / 2\left(U-U_{F B}\right) \quad(\text { in SI units) }
$$

where $C_{d}=$ the capacitance of the semiconductor

$$
\begin{aligned}
\text { per unit area } & \\
\epsilon= & \text { the dielectric constant of the semiconductor } \\
\epsilon_{c} & =\text { the permittivity of free space } \\
e & =\text { the charge on the electron } \\
\mathrm{N}_{\mathrm{T}} & =\text { the net charge density of ionized impurities } \\
\mathrm{U}-\mathrm{U}_{\mathrm{FB}} & =\text { the semiconductor potential relative to the } \\
& \text { flat band potential }
\end{aligned}
$$

In photocapacitance spectra, all of the above are fixed except for $N_{T}$ and of course $C_{d}$. The question thus remaining is how does one relate the density of states of impurities to $\mathrm{N}_{\mathrm{T}}$ at photon energy he. One model is to assume a step function distribution, i.e. an impurity level with a depth 
of $E_{i}$ in the band gap is filled with electrons with photon energy just below $E_{i}$ and completely empty for photon energies just above $E_{i}$. But this kind of behavior is not observed in the spectra and for good reason; it ignores the effect of phonon interaction which would blur the step function and it ignores the fact that at $h \nu=E_{i}$ one expects the impurity level to be half populated if it is in equilibrium with its excited state in the conduction band. A distribution which takes these factors into account is the fermi function $f\left(E_{i}, h \nu\right)=1 /\left(1+e^{E i-h \nu / k T}\right)$ where $k$ is the Boltzmann's constant and $T$ is the Kelvin temperature. Thus the contribution of donor density $\mathrm{N}^{\circ}{ }_{i}$ at energy depth $E_{i}$ to the total ionized states is $N^{\circ}{ }_{i} x f\left(E_{i}, h \nu\right)$. And thus $N_{T}=$ $\sum N_{i}^{\circ} x f\left(E_{i}, h \nu\right)$. This gives

$$
\mathrm{C}_{\mathrm{d}}^{2}\left[2\left(\mathrm{U}-\mathrm{U}_{\mathrm{FB}}\right) / \epsilon \epsilon_{c} \mathrm{e}\right]=\mathrm{N}_{\mathrm{T}}=\sum \mathrm{N}_{\mathrm{i}}^{\circ} \mathrm{f}\left(\mathrm{E}_{\mathrm{i}}, \mathrm{h} \nu\right)
$$

Now we know $C_{d}$ and $h \nu$. If we assume that the energy levels are discrete and fixed we have $\mathrm{C}_{\mathrm{d}}{ }^{2}$ as a linear function of the $N^{\circ}{ }_{i} ' s$. Let $n$ equal the number of discrete energy levels we have chosen. As long as there are more than $n$ measurements of $\mathrm{C}_{\mathrm{d}}$ at different wavelengths, we can do a multiple linear regression to solve for the $\mathrm{N}_{i}$ 's. This is equivalent to doing a least squares fit on the data points $\left(\mathrm{C}_{\mathrm{d}}, \mathrm{h} \nu\right)$ with $\mathrm{N}_{i}$ 's as the parameters.

Choosing the $E_{i}$ 's is very important in this curve 
fitting. They usually are chosen to be evenly spaced, although this is not necessary. If they are chosen too close together, one has too many parameters to fit and their values become meaningless. On a physical level this means that the $E_{i}$ 's near each other become indistinguishable because they are thermally too close. In pratice this has meant that a resolution of $k T$ is toofine, although a resolution of $2 \mathrm{kT}$ works quite well. Some regressions have been done with $1.5 \mathrm{kT}$ resolution.

In the program written for this analysis, called PHTCAP, its multiple regression subroutine can solve up to 25 parameters at a time. If $2 \mathrm{kT}$ resolution is used, a spectra with a width up to $0.63 \mathrm{eV}$ can be analysed in one regression. Spectra of larger widths can also be analysed using this program. This works by fitting a small portion of the lower end (higher wavelength) of the spectra and assigning half of the acquired values (see figure 15). The "window" is then moved over by one parameter. The data is then corrected for the capacitance contributed by the values assigned that are outside the window. Not doing this would give incorrect results at the lower end of the window. The regression for that window is then made and one more parameter is then assigned. Then the window is moved over another unit and the above process is repeated. When the last window is reached, all the remaining parameters are assigned using that regression. A copy of this program is 

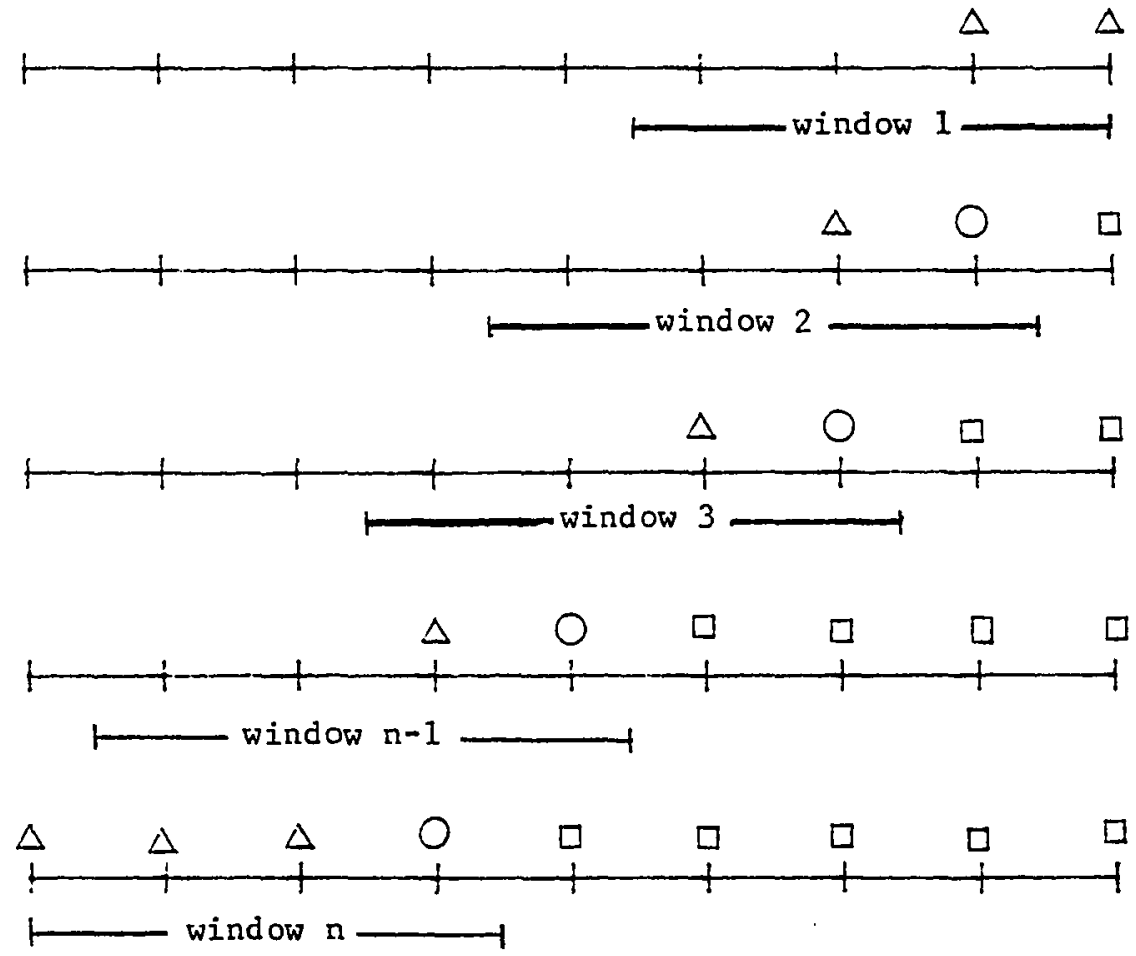

Figure 15.. Stepwise solution to fitting photocapacitance spectra.

$\Delta$ - values assigned for present fitting.

O - values assigned from previous fittings.

a-Values whose contribution to the capacitance

is subtracted. 
given in the appendix.

Examples of some EPS spectra with their analyses are shown in figures 16-18. A sample of p-type gallium phosphide is given in figure 16. Here we see a broad rise of capacitance between 750 and $1100 \mathrm{~nm}$ ( 1.1 to $1.7 \mathrm{eV}$ ), much too wide to be due to one state alone. The analysis indeed shows a broad group of states in this range. A more complex spectrum is shown in figure 17 of a p-type gallium arsenide sample. Aside from several donor and acceptor levels causing decreases and increases in the capacitance there is also a sharp peak in the capacitance spectrum between 1300 and 1400nm. These peaks have been noted in other semiconductors and are attributed to localized excitation levels within the band gap (14). Their analysis is ignored in the program presented here but their position in the band gap is read directly out of the spectrum and the density of states is easily calculated from the peak height.

This particular analysis of these spectra has other limits as well. The Mott-Schottky relationship, on which this model is based, does not hold if the potential is too close to the flat band potential or if the doping level is too low. Thus intrinsic semiconductors analysed by this method would not give realistic results. At photon energies of more than half of the band gap there is the possibility of refilling impurity levels that were depopulated at lower photon energies. This would cause new and more complex 

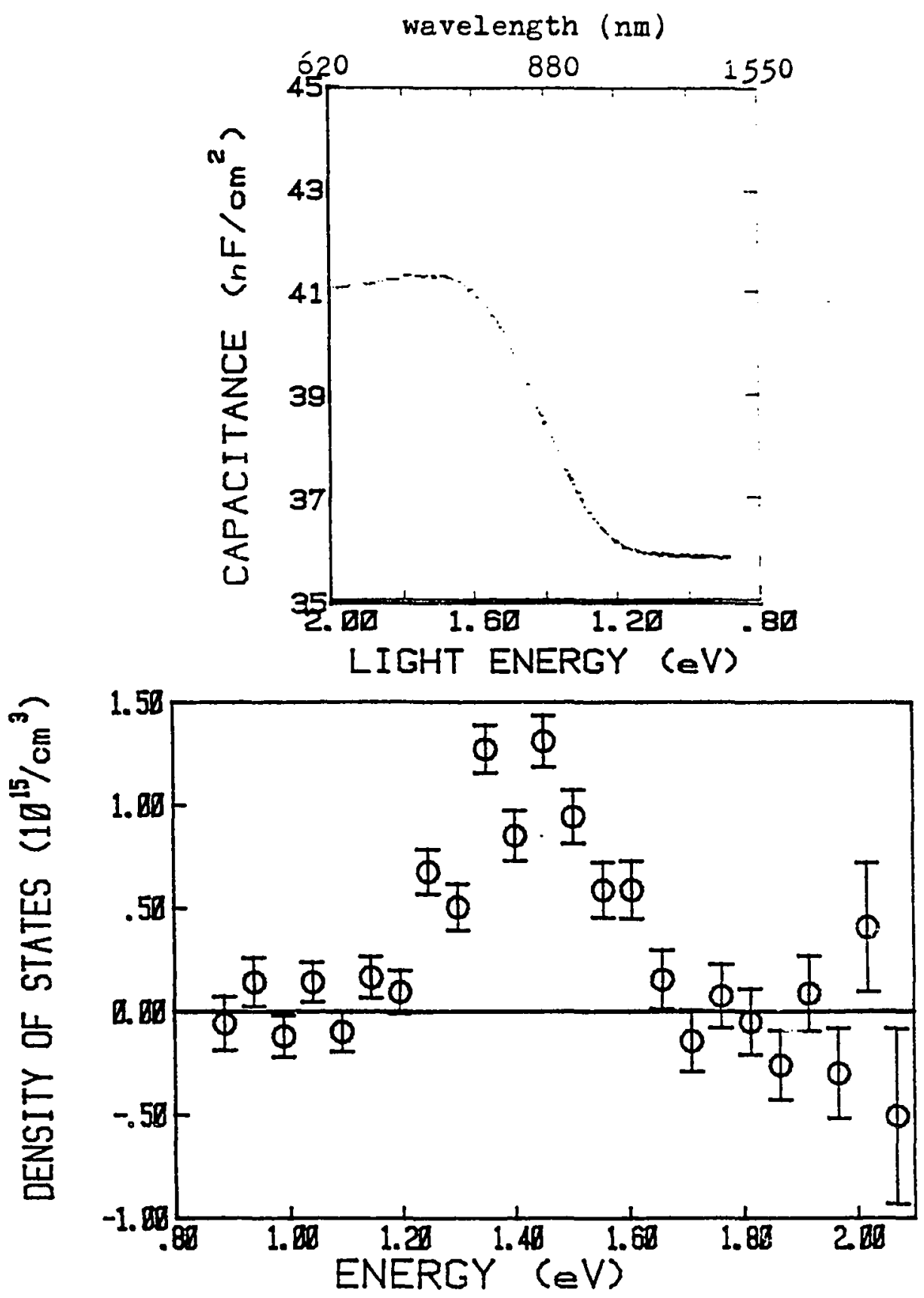

Figure 16. An EPS spectrum of p-GaP with the analysis. 

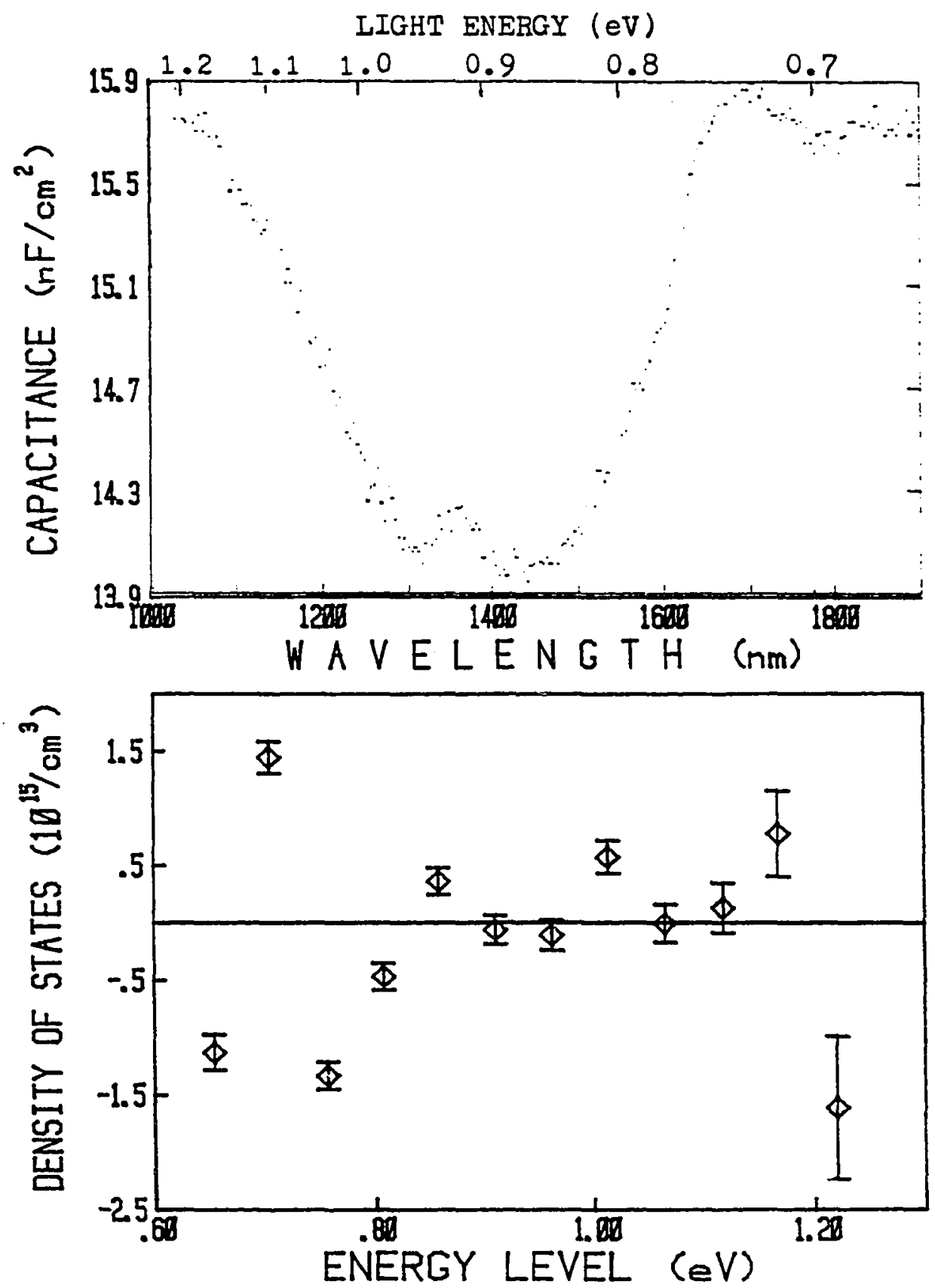

Figure 17. An EPS spectrum of p-GaAs with its analysis. 

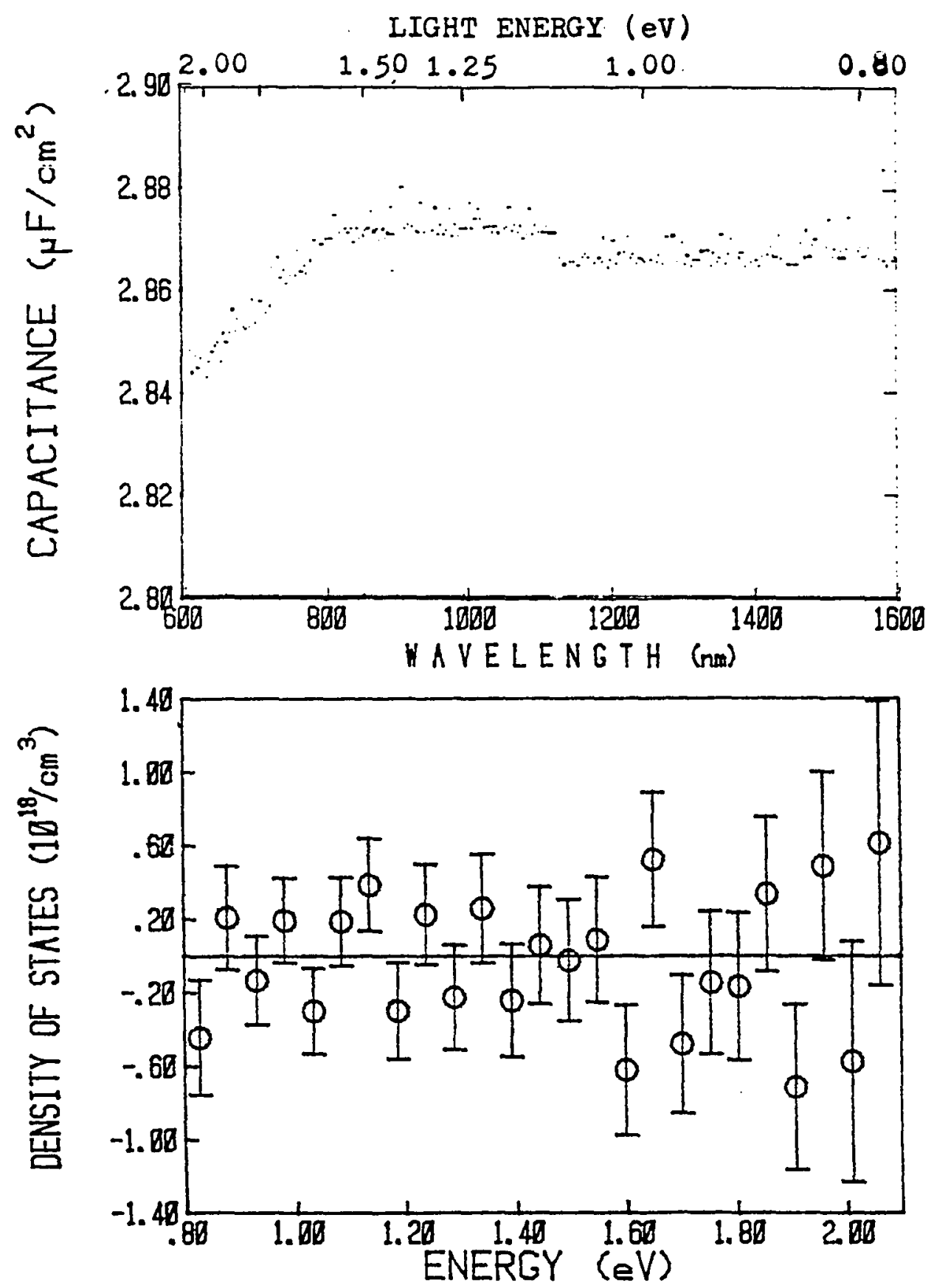

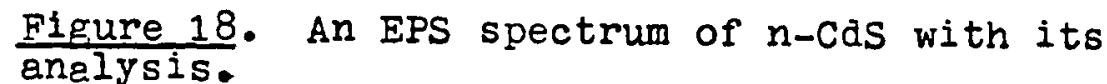


equilibria to be established and would be interpreted by this method to be two impurity levels of opposite type (acceptor,donor). In spite of these drawbacks this method still has wide applicability in analysis of wide band gap semiconductors.

An EPS spectra of a CdS deposit is shown in figure 18. Here we see the spectrum is relatively flat down to $800 \mathrm{~nm}$ $(1.5 \mathrm{eV})$ where the capacitance continually decreases toward the lower end of the spectrum. This is indicative of "very deep" acceptor states which is the type of state that is expected of sulfur as an excess impurity. These acceptor levels could be caused by some other impurity or defect but sulfur is the most likely one. The presence of excess sulfur is not too surprising as this is often the reason that these cathodic deposits have poor semiconducting qualities.

The ability of EPS to detect these impurity levels exemplifies its advanages. To measure these states by other techniques is difficult at best or impossible at worst. Added to this is the benefit of the wide diversity of semiconductors analyzable by this method. EPS will surely become an important tool in semiconductor characterization. 


\section{CHAPTER V}

\section{DISCUSSION}

In the deposition of these cadmium sulfide deposits, sulfur chemistry obviously plays a very important role. For example, the presence of excess sulfur (as elemental sulfur or polysulfides) in as small of an amount as one tenth of a percent yields a semiconductor of very poor quality. For this reason sulfur chemistry will be discussed first, followed by a discussion of the deposition process itself. More specifically, adsorption effects of sulfur will be commented on followed by a discussion of the implications of the differing electrochemical properties of sulfur species. In the light of all of this, the results of deposition conditions will then be related.

Since there are several different electrode processes here, some notation is needed in order to clarify the different methods. Electrode measurements made with the high pressure 1iquid chromatograph and an electrochemical flow cell will be referred to as HLPC-EFC electrodes. The electrode on which CdS is actually being cathodically deposited will be called CD electrodes for cathodic 
deposition. The word "deposits" in the text refers to CdS cathodic deposits.

\section{Sulfur Chemistry}

Adsorption of Sulfur Species Adsorption effects of sulfur was noted on all of the HPLC-EFC electrodes on which sulfur was applied. This effect has also been noted by Baranski and Fawcett(9) who claim that adsorption is an important initial step in CdS formation by this technique. These effects were most greatly noted on electrochemical flow cells when the initial samples of sulfur passed through them. This was always accompanied by a decrease in the background current and usually without the presence of any sulfur peaks. This is a strong indication of sulfur forming a passivating layer on the surface of the HPLC-EFC electrode. After a partial or full covering, bulk sulfur could then be reduced by electrons transferring through the adsorbed sulfur layer, and peaks could be observed. Thus each of these HPLC-EFC electrodes needed conditioning by pre-exposure to sulfur before the sulfur reduction peaks could be observed.

This conditioning effect was greatest with the HPLC-EFC porous carbon electrode, due to the high surface area of this electrode. Conditioning of this HPLC-EFC electrode by HPLC injections took unreasonable amounts of time and was greatly aided by flushing the electrode directly with the 
sulfur sample solution. Other HPLC-EFC electrodes also required conditioning but their smaller surface areas had much shorter conditioning times and this conditioning would be accomplished after just a few injections through the HPLC .

Adsorption on the HPLC-EFC CdS electrode was most evident by the broad peak that appeared after the sharp peak caused by bulk sulfur. That adsorption causes these peaks is evidenced by two facts: this broad peak appears after bulk sulfur has passed through the flow cell, and this peak occurs at potentials higher than necessary for the bulk peak. This higher potential for the adsorbed species also tells us that it is the reactant rather than the product that is adsorbing(28). This adsorption on CdS in general has been noted by others(9) but here it is noted that not only does $\mathrm{S}_{8}$ adsorb but $\mathrm{S}_{7}$ adsorbs as well. Other species of sulfur also may adsorb on CdS.

Adsorption effects on cadmium metal was also observed during the reaction of bulk sulfur with finely divided cadmium. This was a non-Faradaic process, with sulfur solutions being filtered through the cadmium. At room temperature the metal passivates quickly after contact with the sulfur solution. At higher temperatures this passivation still occurs but much more slowly. At higher temperatures adsorption decreases and it is possible that the electrodepositions of CdS are best made near $90^{\circ}$ because 
of the reduction of adsorption. Inclusion of excess sulfur in the deposits because of adsorption could also be causing the deep acceptor levels that are noted in the EPS spectrum. Reactivity of Sulfur Species. The higher reactivity of $\mathrm{S}_{6}$ and $\mathrm{S}_{7}$ is not too surprising having been previously known for $S_{6}$ and suspected for $S_{7}(21,22)$. For example, Bartlett has shown that $\mathrm{S}_{6}$ is more susceptible to attack by tripheny1phosphine and other nucleophiles than is $\mathrm{S}_{8}$ (23). This reactivity is shown on the gold electrode by the lower potentials at which $\mathrm{S}_{6}$ and $\mathrm{S}_{7}$ reduce (see figure 10). For the $C D$ electrode this means that if $S_{6}$ and $S_{7}$ are present then they will reduce before the $s_{8}$. Not only are $S_{6}$ and $\mathrm{S}_{7}$ thermodynamically less stable at room temperature than $S_{8}$ but they react faster as wel1. In figure 12 we see that at higher flow rates (less time exposed to the electrode) $S_{8}$ reduction is kinetically inhibited and only reduces by two electrons per molecule while $\mathrm{S}_{6}$ and $\mathrm{S}_{7}$ are reduced by many electrons per molecule at all flow rates. Thus $S_{6}$ and $S_{7}$ are not only reduced more easily but they are reduced more completely. If $\mathrm{S}_{8}$ were to be incompletely reduced during the CdS deposition, this would lead to excess sulfur in the deposit which could cause the EPS spectrum's deep acceptor levels.

The reactivity of $\mathrm{S}_{7}$ was followed in several experiments. In the filtration of sulfur solutions through cadmium metal at $90^{\circ}, \mathrm{S}_{7}$ was significantly more reactive 
than either $S_{6}$ or $S_{8} \cdot S_{7}$ has also been reported to be very UV sensitive $(19,25)$. This sensitivity was seen here as the conversion of $S_{7}$ to mostly $S_{6}$ over a period of hours. Steudel observed a much more rapid conversion (26) and Tebbe noticed $\mathrm{S}_{8}$ as the decomposition product (19). These discrepancies are not fully understood although they may be due to trace nucleophiles present in solution. The fact remains that $S_{7}$ is less stable than $S_{8}$ or $S_{6}$, which had been expected theoretically for some time (22).

Thermodynamically and kinetically $S_{6}$ and $S_{7}$ has been shown to be more reactive than $\mathrm{S}_{8}$. It is possible that the presence of $S_{6}$ and $S_{7}$ during the deposition of CdS helps to catalyse the reduction of $\mathrm{S}_{8}$ as well as themselves. Their presence may also initiate nucleation sites for sulfur reduction in the bulk solution instead of reducing on the surface on the CD electrodes to form the CdS seed crystals. Whatever the role of $S_{6}$ and $S_{7}$ in these deposits, it is certain that they do react and in all likelihood play an important role.

Deposition Conditions of Cadmium Sulfide

Each of the parameters that was studied here for these CdS deposits is discussed separately below. Much of it is examined in the light of the sulfur chemistry deliberated previously.

Temperature. These deposits were originally made at 
elevated temperatures solely to dissolve enough sulfur. The effects studied here reveal that these temperatures may be necessary in order to reduce the amount of sulfur adsorption on the CD electrode surface during deposition or at least to cause the adsorbed species to react more readily. Adsorption could greatly hinder the deposition mechanism. Even minute amounts of adsorption at these high temperatures (near $90^{\circ}$ ) on the CD electrode could lead to the traces of excess sulfur in the deposits which is one of the causes of the inefficiencies.

Why higher temperatures lead to poorer deposits is not as clear. Hogle(16) showed that CdS is soluble in DMSO at these temperatures in appreciable amounts. It is thus possible that CdS is dissolved into solution enough to cause improper crystal formation on the CD electrode. Another possible cause could be the case at which nucleation sites are formed at higher temperatures. The already sma11 crystals present on the CD electrode could be made even smaller, or even amorphously formed, by a higher number of these sites. Both of these factors lead to smaller crystallites with a greater number of imperfections, causing higher temperature deposits to be less beneficial.

Current Density. At current densities below 0.15 $\mathrm{mA} / \mathrm{cm}^{2}$ deposits of a bright yellow color are formed rather than the usual yellowish orange. This color could be due to the presence of polysulfide salts or even elemental sulfur. 
Again adsorbed sulfur on the CD electrode surface may be the culprit. If adsorbed species reduce only partially or not at all on the surface, these incompletely reduced species could become enclosed in the crystal, yielding the observed color and poor responses.

At higher current densities there is a gradual tapering off of photoresponse. In the electrochemical measurements of sulfur on CdS it was noted that there uas a slow reduction of adsorbed sulfur. Thus at high current densities adsorbed sulfur may be kinetically inhibited causing reduction in the bulk solution instead of reducing on the surface of the $C D$ electrode. This could lead to poor coulombic efficiencies during CdS deposition and cause the poorer deposits. This reduction of photoresponse at higher current densities may also be due to the diffusion limiting current of $\mathrm{S}_{7}$ and $\mathrm{S}_{6}$. Read the next section for details.

Sulfur Concentration. The solutions of these CdS depositions all performed best with sulfur at or near saturation. Sulfur is not a very soluble element and molecular concentrations are thus low. But these concentrations are a factor of ten above what is needed for a diffusion limited reaction at the current densities used for these CdS deposits. It is feasible that these higher concentrations are needed to increase the presence of $\mathrm{S}_{6}$ and $\mathrm{S}_{7}$

The levels of $S_{6}$ and $S_{7}$ in the deposition solution at 
$90^{\circ}$ were measured by HPLC-UV detection. Having taken into account the difference in absorptivity, and assuming that the rate of diffusion is the same as $\mathrm{S}_{8}$, and also assuming that $S_{6}$ and $S_{7}$ reduce completely (12 and 14 electrons per molecule respectively), the potential contribution of these reactive species to the deposition current was calculated. The results give $0.34 \mathrm{~mA} / \mathrm{cm}^{2}$ which is more than enough to account for all of the CdS deposition current and may even explain the tapering off of photoresponse of deposits prepared at current densities above $0.30 \mathrm{~mA} / \mathrm{cm}^{2}$. In reality $\mathrm{S}_{6}$ and $\mathrm{S}_{7}$ must compete with the much more prevalent $\mathrm{S}_{8}$ but their higher and faster reactivity may cause them to be the major reducing species.

Cadmium Ion Concentration. The existence of high concentrations of cadmium ions is necessary for these CdS depositions although the method is not sensitive to the actual concentration. Cadmium ions complex readily with various anions and these affect the CdS deposits(9). Polysulfide species also complex readily with cadmium ions and their formulation during the CdS electrodeposition may be removed by these complexes as they are quite soluble(16). Free uncomplexed cadmium ions may be necessary for these deposits(9) and the excess present during these deposits provides these simple ions.

Bismuth Doping. The correct doping level is important for any semiconductor and these cadmium sulfide deposits are 
no exception. The presence of trace amounts of bismuth greatly improved the photoproperties. Just as important though, this bismuth doping greatly reduced the variability noted for these CdS deposits. Obviously other trace impurities or defects in the crystals were acting as shallow donor levels whose quantities were not very controllable. Bismuth inclusion brought these donor levels up to better and more manageable levels.

\section{Conclusion}

Adsorption of sulfur species plays a very important role in sulfur electrochemistry and this holds for these cadmium sulfide deposits as we11. The higher temperatures needed for these deposits reduce the amount of adsorption and aid the reduction of bulk species on the CD electrodes. This decrease of adsorbed species also helps to eliminate inclusion of excess sulfur which reduces the semiconducting characteristics.

$\mathrm{S}_{6}$ and $\mathrm{S}_{7}$ are reactive enough both energetically and kinetically on electrodes in general to account for a majority of the sulfur reduction on the CD electrodes. Thus $\mathrm{S}_{8}$ may even be playing an inhibitive role by adsorbing and blocking access of these more reactive species to the $C D$ electrode.

The suspected presence of trace amounts of sulfur in the deposits is confirmed by EPS. This new technique of 
measuring deep impuricy levels in semiconductors has application not only here but in a wide variety of semiconductors. The ease at which these spectra are made and the resultant sensitivity make this a promising new method. 
REFERENCES

(1) A. L. Fahrenbruch, I. Cryst. Growth, 39, 73 (1977).

(2) J. J. Loferski, J. of Applied Phys., 27, 777 (1956).

(3) M. S. Wrighton, Chem. \& Eng. News, 3 Sep 1979, pp. $29-47$.

(4) J. W. Sheroham, J. Electrochem. Soc., 128,1817 (1981).

(5) B. Miller and A. Heller, Nature, 262, 680 (1976).

(6) G. P. Power, D. R. Peggs and A. J. Parker, Electrochem. Acta, 26, 681 (1981).

(7) D. K. Roe, L. Wenzhao, H. Gerisher, J. Electroanal. Chem., 136, 362 (1982).

(8) A. S. Baranski and W. R. Fawcett, J. Electrochem. Soc., 127, 766 (1980).

(9) A. S. Baranski and W. R. Fawcett, J. Electrochem. Soc., 131, 2509 (1984).

(10) A. Heller, ed., "Semiconductor Liquid-Junction Solar Cells"; The Electrochemistry Society, Inc.: Princeton, NJ ; 1977.

(11) A. J. Nozik, Ann. Rev. Phys. Chem., 29, 189 (1978).

(12) A. B. Ellis, S. W. Kaiser, and M. S. Wrighton, J. Am. Chem. Soc., 98, 1635 (1976).

(13) A. B. Ellis, S. W. Kaiser, and M. S. Wrighton, J. Am. Chem. Soc., 986855 (1976).

(14) R. Haak and D. Tench, J. Electrochem. Soc., 131, 275 (1984).

(15) M. Aparicio-Razo, Ph.D. Dissertation, Portland State University, Portland, Oregon, (1983). 
(16) H. Hogle, Master's Thesis, Portland State University, Portland, Oregon, (1982).

(17) F. Mondon, J. Electrochem. Soc., 132, 319 (1985).

(18) R. Steudel, H. J. Mausle, D. Rosenbauer, H. Mockel, T. Freyholdt, Angew. Chem., Int. Ed. Eng1., 20, 394 (1981).

(19) F. N. Tebbe, E. Wasserman, W. G. Peet, A. Vatvars, A. C. Hayman, J. Am. Chem. Soc., 104, 4971 (1982).

(20) P. D. Bartlett, E. F. Cox, R. E. Davis, J. Am. Chem. Soc., 83, 103 (1961).

(21) R. Steudel, "Chemistry of the Non-Metals"; W. de Gruyter: New York, 1977; p. 208.

(22) I. Haiduc, "Chemistry of Inorganic Ring Systems, Part 1"; Wiley-Interscience: New York, 1970; pp. 109-120.

(23) P. D. Bartlett, G. Lohaus, L. D. Weis, J. Am. Chem. Soc., 80, 5064 (1958).

(24) M. Schmidt, B. Block, H. D. Block, H. Koepf, E. Wilhelm, Angew. Chem. Internat. Ed. Eng., 7, 632 .

(25) R. Steudel, Technischen Universitaet of West Berlin, personal communication, 1985.

(26) R. Steudel, H. J. Maeusle, Z. Anorg. Allg. Chem., 478,156 (1981).

(27) G. L. Miller, D. V. Lang, L. C. Kimerling, Ann. Rev. Mater. Sci., I, 377 (1977).

(28) A. J. Bard, L. R. Faulkner, "Electrochemical Methods"; Wiley: New York, 1980; p. 527. 


\section{APPENDIX}

A PROGRAM IN FORTRAN THAT ANALYSES

ELECTROCHEMICAL PHOTOCAPACITANCE DATA 


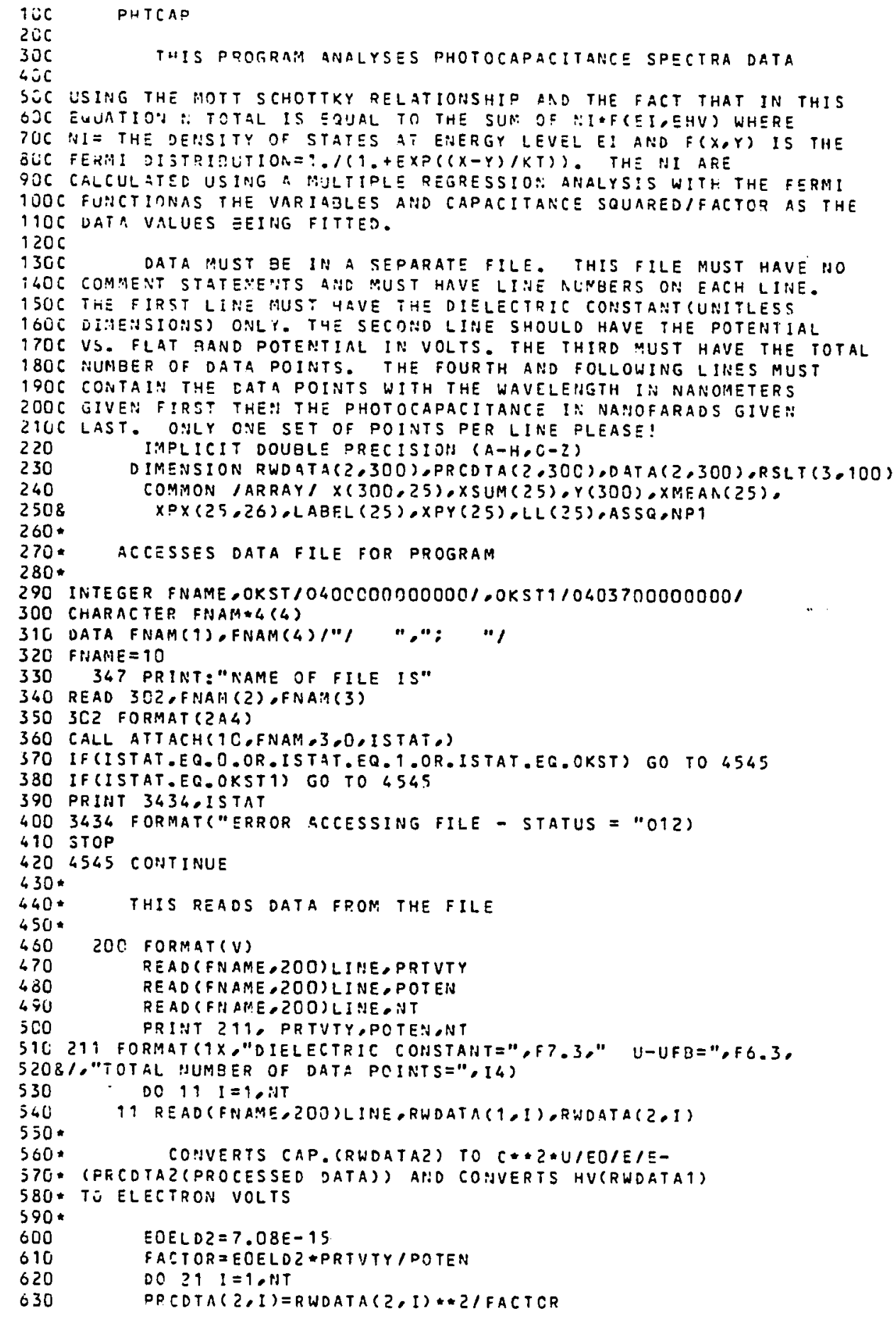




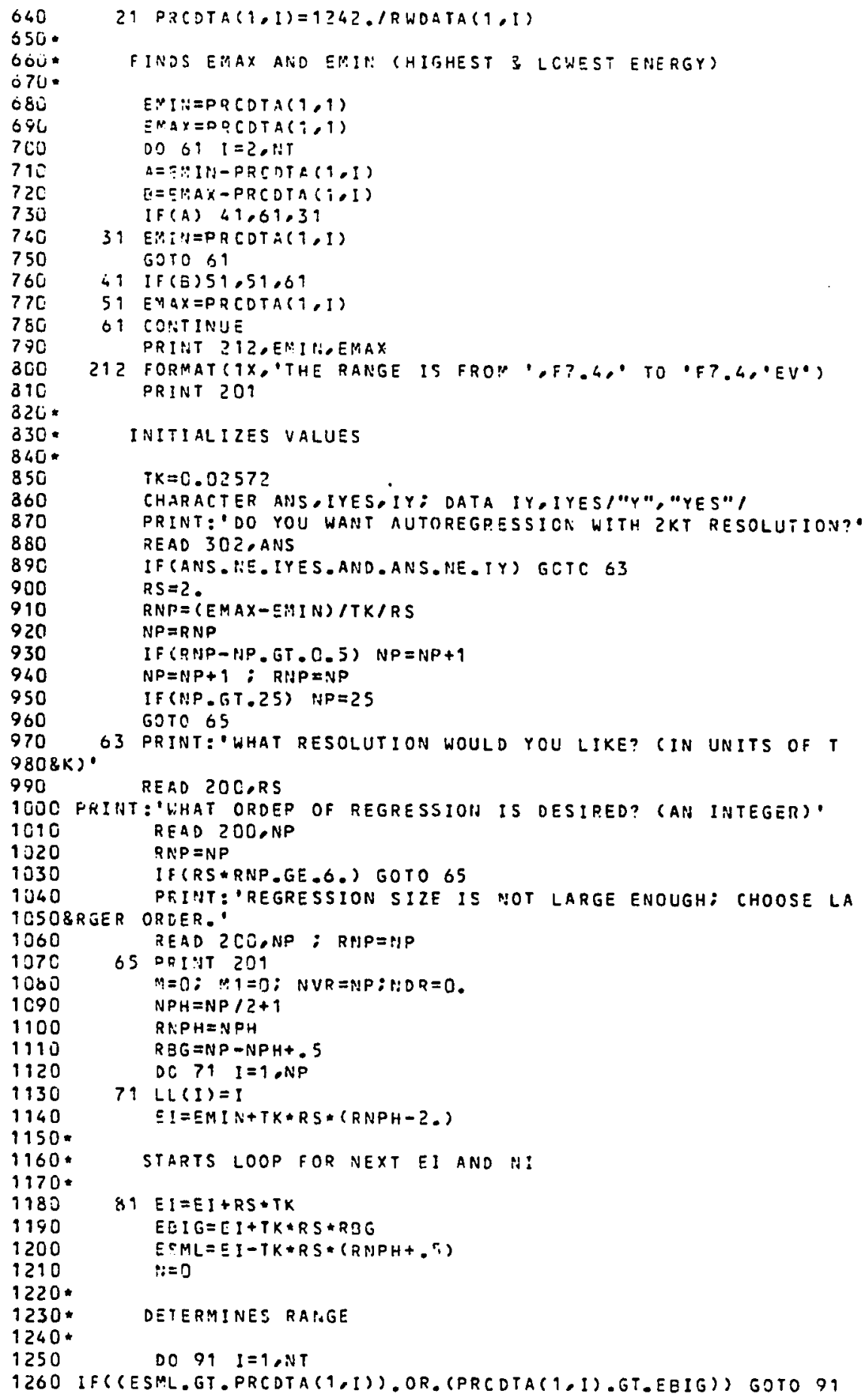




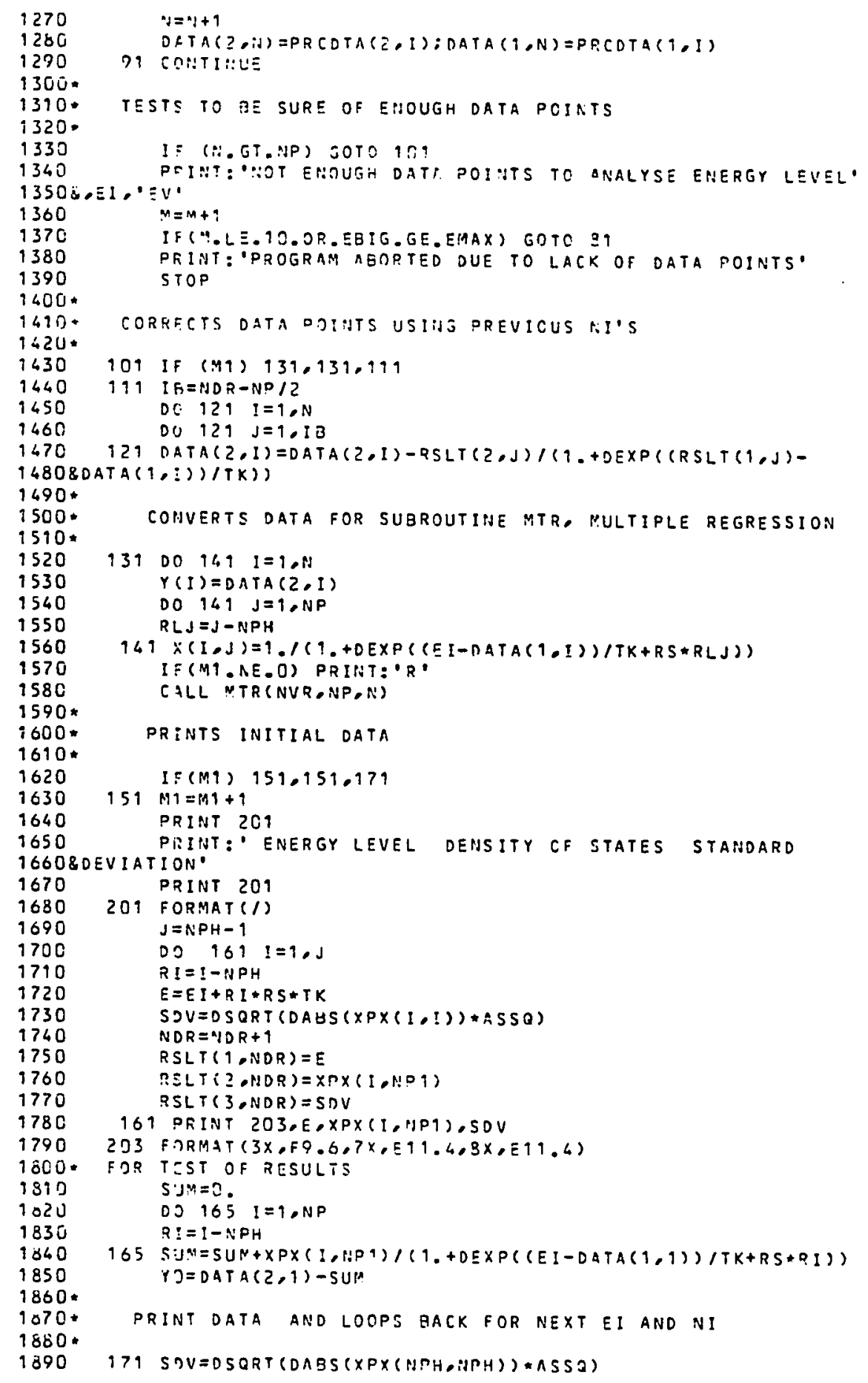




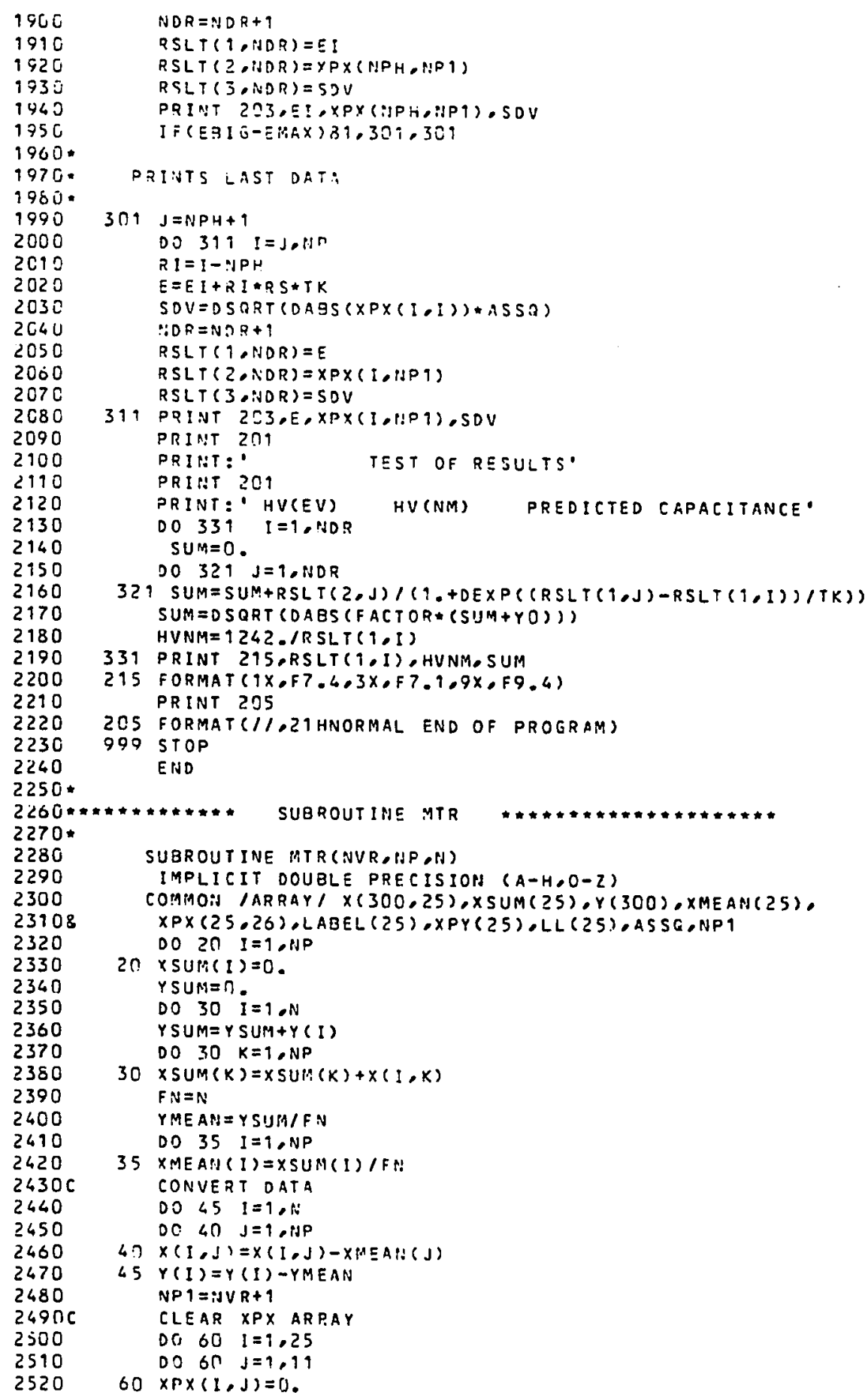




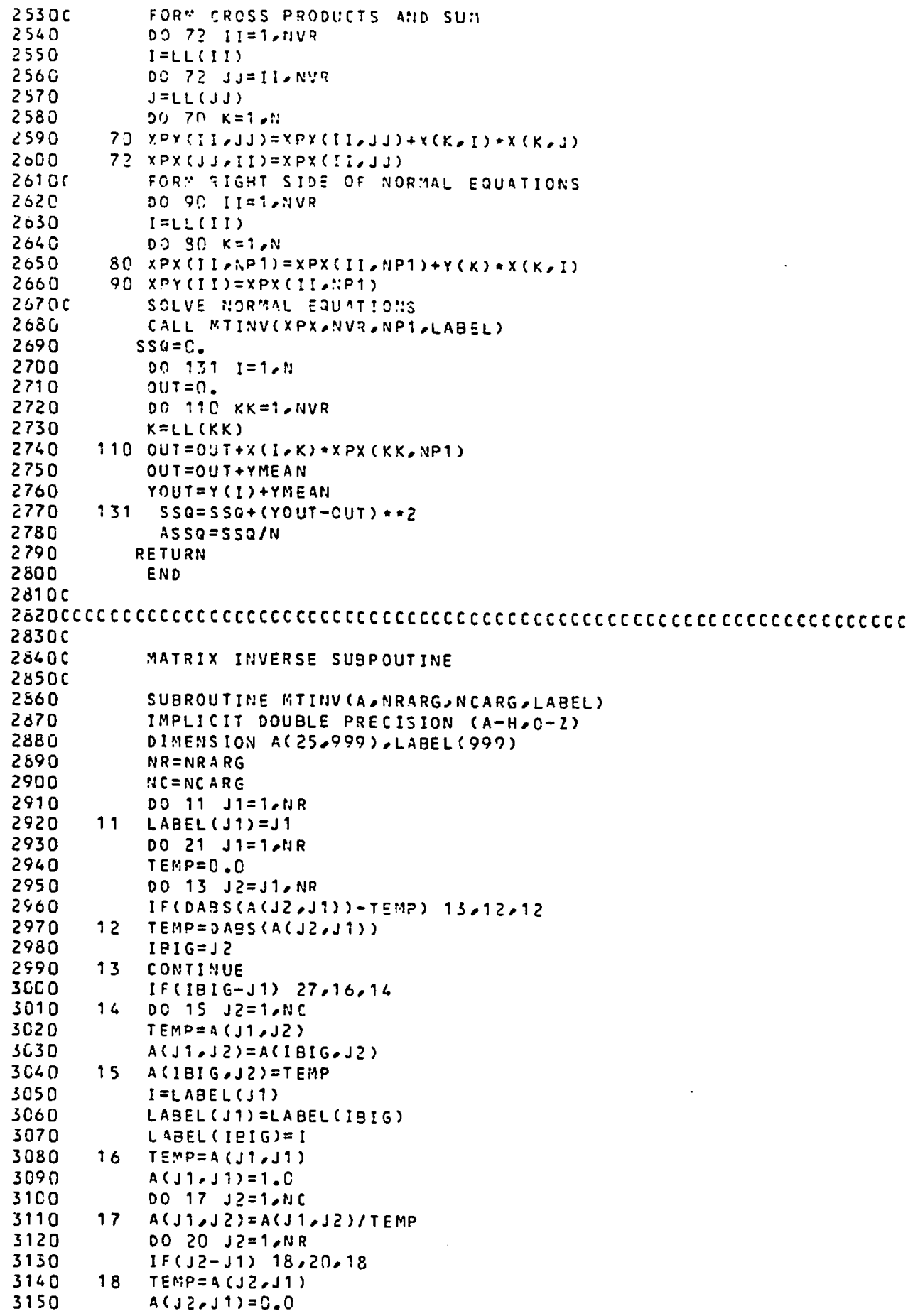




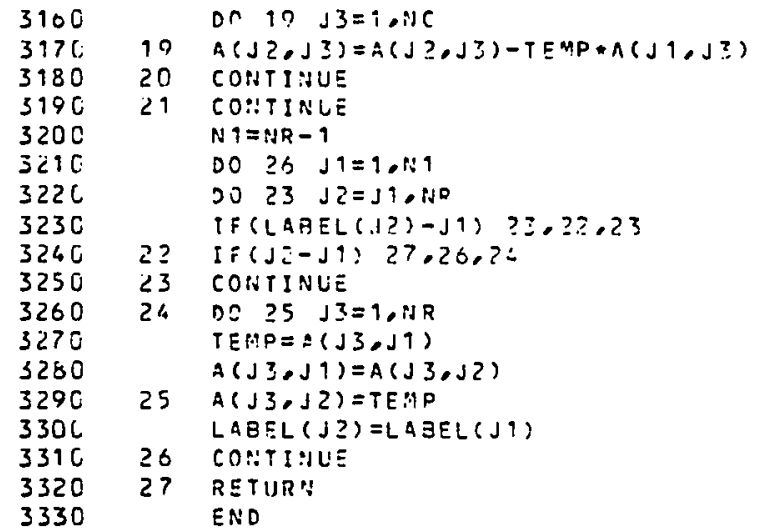

